\title{
Ser indígena como un asunto transicional: primordialismos e instrumentalismos
}

\section{"Nunca nos dijeron que éramos indígenas": tránsitos hacia "lo muisca"}

$\mathrm{T}$

res pequeños sucesos registrados durante mi trabajo de campo se conectan y nos introducen a nuevas rutas de sentido para comprender otros elementos que configuran el campo etnopolítico muisca. El primero ocurrió en Suba, cuando fui por primera vez a la sede del cabildo indígena, ubicada cerca de la plaza fundacional del antiguo pueblo — hoy localidad de Bogotá-, y Myriam Martínez Triviño, gobernadora en su momento, me presentó a un señor de la comunidad como el representante del Cabildo Muisca de Suba ante la Ascai (Asociación de Cabildos Indígenas de Bogotá), quien vestía elegantemente. Empleando una forma de hablar muy propia de un pequeño burgués bogotano con formación universitaria, se dirigió a Myriam para responderle: "sí... en esto de lo muisca llevo como cuatro meses" (el énfasis es mío). El segundo suceso fue durante una reunión en la sede del Cabildo Muisca de Bosa, en el barrio San Bernardino de esa localidad urbana, a la que asistí como director de un equipo universitario de investigación. Aquella vez tomó la palabra Gustavo Chiguasuque, miembro del consejo de mayores de la comunidad muisca de Bosa, órgano que existe hace aproximadamente una década. En su calidad de mayor de la comunidad, Gustavo recordaba que ser muisca fue resultado de un proceso de aprendizaje: "Nunca nos dijeron que éramos indígenas”, expresó en un momento. El tercero ocurrió durante 
una conferencia a cargo de algunos integrantes de la comunidad muisca de Bosa, en la Cátedra de la Memoria Mhuysqa Carlos Mamanchée ${ }^{28}$ La abuela Ana Cecilia Chiguasuque, vestida con su túnica blanca ornamentada con motivos geométricos de color terracota, hablaba en la tarima del Teatro Cádiz de Bogotá mientras tejía. Su primer enunciado concordaba con las palabras de Gustavo: "Decían que no existíamos [...] estamos en ese reconocimiento [...] nos considerábamos campesinos, labradores [...] no conocíamos la palabra indígena [...] muchos abuelos se fueron sin saberlo".

Aunque la conservación de ciertos elementos culturales, sobre todo los relacionados con el territorio, les asigna el atributo de permanencia espacial a algunas comunidades de herencia muisca del altiplano cundiboyacense, ser muisca parece ser un estado determinado por instancias temporales; llegar o andar "en lo muisca" o saberlo y asumirlo como denominación de la propia identidad es un asunto transicional.

Como herencia colonial, las palabras indio e indigena connotaban - y todavía para muchos - un ser vil, peligroso, sucio y bruto. Con las políticas liberales de modernización del país a partir del siglo XIX y la repartición de los resguardos indígenas en Cundinamarca, el muisca quedó condenado prácticamente a la desaparición. Su existencia solo era referenciada como parte del pasado (Restrepo, 2005). Las comunidades de Cota y Chía, que durante el siglo xx fueron consideradas como comunidades civiles y con alto grado de aculturación (Wiesner, 1988), se mantenían cohesionadas socialmente, pero denominarlas con la palabra indígena no parecía ser tan apropiado, de ahí que se reemplazara por otras categorías, como las de nativo, originario del territorio o campesino. El uso consolidado e incorporado de la palabra en cuestión vino a darse casi a finales del siglo Xx, a través de las nuevas

28 Inicialmente se llamaba Cátedra Muisca. A partir de la versión del 2013 se denominó Cátedra de la Memoria Mhuysqa Carlos Mamanché, en honor al líder fundador de la comunidad muisca de Sesquilé. Consistió en un espacio de seminarios y charlas donde líderes comunitarios, memorialistas nativos y colaboradores (arquitectos, artistas, militantes neoindigenistas e investigadores amateurs) participaban de discusiones y exposiciones quincenales en torno al tema muisca. 
generaciones que, incluso, tuvieron que convencer a sus abuelos de que eran indígenas. Tal variación sociolingüística estuvo enmarcada en los contextos políticos que a partir de los años sesenta transformaron el campo étnico en Latinoamérica y que, en Colombia, se concretaron más adelante con la proclamación de la Constitución Política de 1991.

El nuevo contexto político impulsó dos derechos que, en el marco de la "etnogénesis" o "reivindicaciones autogestionarias" (Gros, 2000) de nuevos o fortalecidos grupos indígenas, se convirtieron en campos de poder y de luchas: el autorreconocimiento y la autonomía. El primero obligaba a que las comunidades, nuevas o perdurables, se convencieran a sí mismas de su condición étnica diferencial y lo asumieran como proyecto social, cultural y político. El segundo determinaba que había que convencer al mundo exterior, y sobre todo a las instituciones estatales, de su permanencia y existencia como grupos diferentes de la sociedad mayoritaria, para así poder reclamar su derecho a autogobernarse y decidir su destino como colectividad. La idea de convencerse a sí mismo y convencer a otros reitera que la etnicidad es un campo configurado por múltiples tránsitos.

Así mismo, los campos conflictivos del autorreconocimiento y de la autonomía revelan una vieja disputa entre dos enfoques o maneras de entender la identidad étnica: el primordialista y el instrumentalista. Tal debate oscila entre la etnicidad en cuanto conjunto de elementos esenciales, prefijados y ligados estrechamente a los lazos emocionales que cohesionan al grupo y la etnicidad en cuanto artefacto socialmente construido, racionalizado y agenciado de manera estratégica para transformar las condiciones políticas del colectivo (Fenton, 2005, pp. 73-76; Hutchinson y Smith, 1996, pp. 8-9). En la introducción de este libro aclaré que la presente investigación asume el primordialismo y el instrumentalismo no como categorías que caracterizan la totalidad de los procesos etnopolíticos - lo que obligaría a elegir entre uno y otro enfoque-, sino como instancias o momentos que son activados de acuerdo a ciertas circunstancias, incluso tan personales y privadas, que nos llevan a hablar de la heterogeneidad en cuanto a cómo interpretar y asumir la identidad del colectivo. Por esa razón, he preferido nombrarlos en plural: primordialismos e instrumentalismos. 
Por su parte, Anthony Smith elabora una crítica a los enfoques que durante la década de los noventa del siglo xx estudiaron la relación entre la etnicidad y la política. Para él, los estudios privilegiaron la meta de entender cómo los marcos normativos influían a los movimientos étnicos y nacionalistas y dejaban a un lado la influencia de estos últimos en las políticas nacionales y globales. Además critica los enfoques que denomina "posmodernos", los cuales asumen la etnicidad como artefacto cultural y a las identidades como constructos con alto grado de plasticidad y de acomodación (1996, pp. 445-447). Para el caso muisca, he asumido que el campo etnopolítico está compuesto precisamente por la intersección y la tensión de las dos rutas que inicialmente propone Smith. Respecto a la plasticidad, no la satanizo; considero que puede caracterizar un proceso de reconocimiento étnico que, al atravesar múltiples tránsitos, involucra la dimensión estética en la política. Esta idea se deriva de otra propuesta desarrollada en un trabajo anterior a la que denominé "la performancia en las identidades muiscas actuales” (Gómez Montañez, 2010). Al fin y al cabo, como lo propone Christian Gros, "la identidad está allí para verse" (2000, p. 71. El énfasis es mío).

Sea para comprender cómo la identidad muisca ha sido asumida durante coyunturas político-administrativas, por ejemplo, en el caso del representante de Suba ante la Ascai, o como una denominación que se acepta y de la que se aprende, por ejemplo, en el caso de los mayores Chiguasuque de Bosa, este capítulo explora la faceta transicional de la identidad indígena muisca, enmarcada por las transformaciones políticas y culturales que inspiraron y fueron inspiradas por la Constitución Política de 1991. Postulo y reitero que la etnicidad es un asunto de tránsitos que suele activarse en momentos críticos y que eso le da su carácter performativo. Las crisis generan transformaciones, y estas pueden concretarse tanto en nuevos niveles y facetas del autorreconocimiento étnico en las comunidades oficialmente reconocidas por el Estado, como en la emergencia de nuevos grupos que, desde la misma condición mestiza de sus miembros, congregan personas individuales y familias que optan por transitar hacia una identidad indígena y con esta afirmar y consolidar un estilo de vida y pensamiento alternativos a los de la ciudadanía en general. Esto también nos permite 
introducir una variedad de organizaciones que, como la autodenominada PNMC, ingresan al campo etnopolítico muisca para confrontarlo y contribuir a su heterodoxia.

\section{Crisis y tránsitos: la performancia del campo etnopolítico muisca}

Victor Turner propuso entender el mundo social como un conjunto de procesos y transiciones y, para eso, él mismo transitó del modelo ritual al performance. En su etapa académica más estructuralista, Turner se inspiró en los estudios de rituales de Van Genep e identificó en estos una estructura diacrónica que comprendía tres etapas: separación del mundo profano, alejamiento de la vida secular y regreso renovado a la vida cotidiana (1998a). El sujeto que atravesaba un proceso de iniciación retornaba de un momento ritual crítico sin ser el mismo; era una analogía, pero no una copia del original. Casi veinte años después, cuando desarrolló su concepto de performance, este comprendía cuatro etapas que explicaban la dimensión procesual de lo social. La primera etapa era de latencia, en la que la vida cotidiana trascurre; la segunda, de crisis, cuando emerge una situación que confronta dicha cotidianidad; la tercera, de despliegue del aparato normativo para enfrentar la crisis, en la que se presenta la liminalidad, es decir, el momento transicional en el que los procesos permanecen en la frontera del cambio sin ubicarse en una u otra etapa; y la cuarta, de transformación y retorno al estado de latencia (Turner, 1988b).

Este modelo performativo, crítico o transicional, puede ser aplicado para entender las transformaciones del campo etnopolítico a niveles global y nacional, en las que tanto las identidades étnicas como las políticas y normatividades se vieron involucradas en la segunda mitad del siglo Xx. La consolidación de un movimiento indígena ${ }^{29}$ en varios países como medio de reivindicación cultural, la nueva jurisprudencia

29 El movimiento indígena fundacional del Cauca, que se había unido institucionalmente a la ANUC (Asociación Nacional de Usuarios Campesinos) desde los años sesenta en el contexto de la reforma agraria, en 1972 reclamó diferenciar los asuntos indígenas de aquellos del campesinado y formó el CRIC, 
internacional favorable a los pueblos indígenas y las consecuentes reformas constitucionales fueron los factores que desde el plano político contribuyeron a la aceptación del carácter multicultural y pluriétnico de las naciones latinoamericanas (Engle, 2010; Sieder, 2002). En Colombia, el movimiento indígena colombiano, que tenía sus antípodas en la lucha por la tierra en Cauca y Tolima y que se había fortalecido con las reformas agrarias de los años sesenta, ahora encontraba un escenario propicio para transformar su papel en la construcción de la nación, mediante su participación en la política electoral (Laurent, 2005) y en una gubernamentalidad que requería la "construcción de un nativo ecológico" (Ulloa, 2004). La Constitución Política de 1991 concretó a nivel nacional los derechos colectivos para pueblos indígenas que el Convenio 169 de la OIT había consolidado para las naciones democráticas del mundo (Correa Rubio, 1993; Gros, 1991, 2000). Esto contribuyó a consolidar un nuevo campo etnopolítico nacional cuyo centro estuvo ocupado - y ha permanecido hasta ahora- por los nasas, los misaks, los emberas y grupos indígenas de la Sierra Nevada de Santa Marta (los ikas, los koguis y los wiwas), mientras que la etnia muisca, que históricamente se había consolidado como la base del pasado precolombino de la nación (Botero, 2006; Langebaeck, 2009), quedó en las márgenes ${ }^{30}$. Aun así, el nuevo contexto político influyó notablemente dentro de comunidades muiscas como Cota y Chía, en el fortalecimiento de sus instituciones y territorios, y para los casos de Sesquilé, Suba y Bosa esto significaba su tránsito hacia la existencia como comunidades indígenas renovadas.

Jimmy Fiquitiva, muisca de Cota, desde una posición un poco distante de los asuntos administrativos del cabildo indígena, nos brinda una referencia temporal de lo que él mismo denomina el boom de lo indígena en su propia comunidad:

que se convirtió en la organización indígena colombiana por antonomasia (Boud, Koonings, Oostindie, Ouweneel y Silva, 1996; Castillo, 2007).

30 Un análisis de esta situación marginal de la etnia muisca en el campo etnopolítico colombiano es expuesto de manera más profunda en mi artículo "Esbozo de una antropología de lo muisca desde una perspectiva del sur: paralelos y tránsitos” (Gómez Montañez, 2013b). 
Antes de que llegara Joaquín [su primo] al poder sí estaba perdido [el reconocimiento como cabildo] porque era muy difuso. Iban a las elecciones gente muy particular, gente que estaba en la lucha por la causa, entonces no se hacían asambleas grandes porque a la gente no le interesaba. O sea, como que todo este boom de otra vez esta serie de conceptos de resguardo, de comunidad, como que empieza otra vez a resurgir a partir, póngale usted, de los años ochenta pa'cá. (Jimmy Fiquitiva, 15 de junio del 2012)

El boom indígena logró sintonizarse con el marco político propuesto por la Constitución de 1991. Las disposiciones del Convenio 169 de la OIT se concretaron ese mismo año con la promulgación de la Ley 21. Bajo esta, los pueblos indígenas, en cuanto sujetos de derechos colectivos, quedaron exentos de demostrar que todas sus instituciones permanecían prácticamente intactas como prueba de su existencia. Según el análisis realizado por François Correa Rubio, en esta ley se incluyen criterios de transformación histórica y territorial-estatal que afectaron a las comunidades durante largo tiempo. Se estableció además el criterio subjetivo del autorreconocimiento o autodeterminación como fundamental para definir la identidad indígena (2011, p. 91). Esto implicaba de alguna manera una ventaja para grupos étnicos que, como el muisca, no parecían contar con claros indicadores objetivos de existencia diferencial respecto al campesinado. Correa Rubio afirma que en 1995, sin embargo, se dio un retroceso en el campo jurídico con la expedición del Decreto 2164, el cual revisó la condición de ser indígena al definir en su artículo 2 a la comunidad o parcialidad indígena como:

el grupo o conjunto de familias de ascendencia amerindia, que tienen conciencia de identidad y comparten valores, rasgos, usos o costumbres de su cultura, así como formas de gobierno, gestión, control social o sistemas normativos propios que lo distinguen de otras comunidades, tengan o no títulos de propiedad, o que no puedan acreditarlos legalmente, o que sus resguardos fueron disueltos, divididos o declarados vacantes. (Correa Rubio, 2011, p. 93)

Aunque el decreto parecía ratificar la aceptación de la historicidad de los grupos, sus transformaciones y la "conciencia de identidad" como 
condición de reconocimiento étnico oficial, la verdad es que le quitó el peso jurídico al autorreconocimiento como criterio fundamental para reconocer a las poblaciones indígenas, pues en un parágrafo le reserva al Estado la definición de lo indígena, aunque causa sorpresa que sea en manos del Incora (Instituto Colombiano de la Reforma Agraria) ${ }^{31}$, una entidad dedicada a los asuntos agrarios:

En caso de duda sobre el carácter y la pertenencia a un pueblo indígena de una colectividad, el Incora deberá solicitar al Ministerio del Interior la realización de estudios etnológicos con el propósito de determinar si constituye una comunidad o parcialidad indígena. (Correa Rubio, 2011, p. 93)

La legislación colombiana obligaba entonces a que las comunidades se convencieran a sí mismas de su condición étnica al tiempo que convencían a las instituciones estatales. Como parte del andamiaje burocrático y de los dispositivos para hacerle frente a los momentos críticos y coyunturales, las comunidades muiscas atravesaron procesos de fortalecimiento cultural, innovaron sus métodos de cohesión social y mejoraron sus conocimientos políticos y administrativos para poder integrar los trámites burocráticos y la reivindicación colectiva como comunidades indígenas. Henry Neuta, exgobernador del Cabildo Muisca de Bosa, expone su versión de esta integración en el marco político coyuntural de 1991:

Yo creo que la Constitución del 91 permite abrir una brecha digamos imaginaria en todos los pueblos, en todas las partes que articulan dentro de la comunidad, donde se vienen construyendo muchas cosas, para articular esos derechos que se recibieron ahí,

31 El Incora fue creado mediante la Ley 135 de 1961. Fue la entidad estatal encargada de determinar los criterios de repartición de tierras aprobados en la reforma agraria. Por tanto, también le correspondía administrar los asuntos de resguardos o territorios indígenas como entidades territoriales de protección especial. En el 2003, el Incora se convirtió en el Incoder (Instituto Colombiano de Desarrollo Rural) y fue liquidado en el 2016, por un decreto del 15 de noviembre del 2015. Desde ese entonces hasta la fecha, en el marco de los Acuerdos de Paz entre el gobierno colombiano y la guerrilla de las Farc-ep, la Agencia Nacional de Tierras es la entidad encargada de estos asuntos. 
materializarlos en la realidad. Entonces en eso digamos que los pueblos indígenas han venido caminando, se han venido preparando, han venido entendiendo la legislación, cómo adaptar la ley propia a la legislación nacional, y eso ha permitido que algunos líderes construyan herramientas que armonicen eso [...]

Entonces yo creo que de una forma u otra la Constitución sirvió, por un lado, porque le permitía a esos pueblos que venían afectándose desde su tradición a decir: "Bueno, aquí hay un punto de partida porque está reconociendo los derechos y vamos a trabajar sobre eso". Para que la institución y el Estado reconozca los derechos, ¿qué nos toca? Fortalecernos desde la tradición, lo que se había dejado hasta cierto punto toca volverlo a retomar para generar pervivencia, de lo contrario es muy difícil. Porque alguna vez me decía una antropóloga de la Secretaría de Gobierno: “No, es que la Constitución, no sé dónde dice, que en la medida que los pueblos indígenas pierdan usos y costumbres están perdiendo derechos". Pues no sé hasta dónde sea cierto, hasta dónde sea verdad. Pero nos toca manejar así, de cierta manera lo entiendo así porque cómo vamos a hablar de, y yo lo he dicho en mis asambleas, desde dónde vamos a exigir, desde la silla del colombiano o desde la silla de la tradición de los pueblos indígenas. Cómo puedo exigir algo desde lo indígena si no me lo creo, si no lo vivo, si no lo entiendo. Entonces cuando la construcción del Ministerio ${ }^{32}$, abre las puertas para el reconocimiento de los pueblos indígenas, entonces fue como una ola, una ola simbólica que llegó a esas familias que dijeron acá hay unas tradiciones que hemos vivido históricamente, porque mi papá me la enseñó, mi abuelo se la enseñó a mi papá, a mi abuelo se lo enseñó su papá. Entonces bajo esas consideraciones comenzó a resurgir el pensamiento de que éramos una comunidad bajo unas características de vida. (Henry Neuta, 24 de agosto del 2012)

32 Se refiere a que el Ministerio del Interior y de Justicia, mediante su División General de Asuntos Étnicos, es el que se encarga del proceso de reconocimiento de las comunidades indígenas en Colombia. 
Si aplicamos el modelo performativo de Turner, tenemos entonces que la Constitución de 1991, con todo y sus resultantes leyes y decretos contradictorios, significó un evento coyuntural en la política colombiana que permitió el despliegue de múltiples dispositivos burocráticos para demostrar la condición étnica muisca y transformar su posición en el campo etnopolítico. Por su parte, las mismas comunidades en su interior replicaron esos mismos procesos, que en parte eran rituales. Como veremos en los siguientes apartados, la denominación indígena muisca y su incorporación individual y colectiva fue activada y transformada en momentos críticos, por lo general cuando su condición diferencial de existencia estuvo amenazada. En términos amplios, el modelo se replica así: en primer lugar, se pone como meta el convencimiento colectivo de la conciencia étnica, impulsada, por lo general, por un requerimiento institucional. Luego vienen crisis en las que se evidencian que no todos los miembros de la comunidad transitan de la misma manera hacia su aceptación; incluso, dicha heterodoxia con sus respectivos conflictos puede generar crisis internas que afectan la existencia del colectivo. Y finalmente, para hacerle frente a las crisis, se establecen nuevas ritualidades internas pero, sobre todo, aquellas de índole institucional, y el ciclo vuelve a comenzar.

Los primordialismos e instrumentalismos también se activan, pero como lo argumenté al inicio de este capítulo, la condición étnica resulta de la tensión entre ambos campos. En cuanto a los instrumentalismos, según lo encontrado en el trabajo de campo y en los testimonios orales, diré que se manifiestan a través de dos vías: por un lado, el tránsito por funciones e identidades que permiten que las personas puedan oscilar y desplazarse entre sus condiciones de indígenas, mestizos, campesinos, comuneros, propietarios y ciudadanos, y, por otro, el uso de canales y relaciones políticas internas y externas para ejercer el poder y lograr transformar las condiciones individuales y colectivas. Si aplicamos la teoría de la práctica social de Pierre Bourdieu (Bourdieu y Wacquant, 1995), veremos que el primer elemento forma parte de los "habitus" y; el segundo, de los “capitales simbólicos" en el campo de la etnicidad muisca. Vale aclarar que al aplicar el término instrumentalismo no se quiere decir, como muchos suelen pensar, que la condición étnica sea un invento de estas comunidades, y que se quita o pone 
por conveniencia. Sin embargo, también es relevante tener en cuenta que las identidades étnicas sí se activan y que las acciones de las organizaciones indígenas avanzan de una u otra manera a medida que se transforma el campo político que las reconoce y valida. Respecto al primordialismo, como la dimensión esencial de la identidad étnica que activa los lazos afectivos comunitarios, señalaré que emerge cuando es necesario darle un contenido a la instrumentalización, en otras palabras, cuando se acepta la denominación indígena, otorgándole ciertos elementos característicos que habían permanecido tácitos en las familias y comunidades. En palabras de Gros:

No se puede de ninguna manera instrumentalizar por mucho tiempo una identidad, movilizarla con fines internos y externos sin interrogarse sobre su contenido, sin inscribirla en el tiempo y dentro del espacio. En el tiempo, porque definirse como indígena significa ciertamente afirmar su pertenencia a una comunidad, es decir, a una etnia, en el seno de una sociedad dada, pero supone también que se establezca claramente una inscripción de esta comunidad en la historia. (2000, p. 70$)$

A diferencia de lo propuesto por Gros, no considero que el instrumentalismo venga antes que el primordialismo, o viceversa. Ambos coexisten en continua tensión. Un ejemplo representativo es, nuevamente, el de la comunidad de Bosa. En el capítulo anterior, la líder Victoria Neuta no solo defendía con vehemencia a los cabildos urbanos, sino que además reiteraba que la condición étnica de su comunidad no era ni un invento ni algo que se dio de un momento a otro, sino que tenía sus raíces en el pasado de varias familias que vieron amenazada su vida rural y fueron obligadas a asumir los problemas de la expansión urbana. Al pronunciarse así ante un auditorio académico, y en cierta manera político, quiso obviar lo que Carlos Durán (2004; 2005) registró en su trabajo de campo: el reconocimiento de una conciencia étnica y el reconocimiento oficial en Bosa habían comenzado como un proceso jurídico asesorado por un abogado, en momentos coyunturales y críticos. Tanto la posición de Victoria como aquella cierta verdad jurídica ponen en evidencia las tensiones entre la esencialidad del primordialismo y la racionalidad del instrumentalismo. Sin embargo, 
su pasión discursiva no permite saber cómo los comuneros de Bosa asumieron dichas tensiones.

Henry Neuta, por su parte, establece una relación coherente entre el lado político-estratégico y el lado esencial-primordial —y romántico- de la conciencia étnica de su comunidad; no niega que un factor fundamental para ello, aunque lo sepa de oídas, fue una consultoría jurídica, pero, además sabe que, como lo indica Gros (2000), la instrumentalización requiere de contenidos que vinculen a las comunidades y organizaciones étnicas con su historia. En este caso, entonces, la sugerencia de un abogado sumada a las experiencias de otros pueblos indígenas motivaron el trabajo de fortalecimiento de conciencia étnica en Bosa.

Lo que yo he escuchado, alguien llegó y les dijo: "Bueno, con estas problemáticas así, que esto y esto, ¿ustedes no son indígenas?" $\mathrm{Y}$ entonces algunos de los mayores cuentan que en esas reuniones, uno dijo: "Sí, nosotros somos indios, muchos somos marmatos de acá". Es una palabra que dice que "es de aquí". Entonces bajo esa consigna llegó alguien y “¿ustedes no son indígenas? [Henry corrige] ¿ustedes no son indios?”. Como que sembró ese cuestionamiento en algunas personas. Ya algunos entonces, entre todas las comunidades entraron personas que les quedó sonando y empezaron a trabajar $[\ldots]$

Cuando empezamos a hablar de lo indígena, cuando se crea el cabildo y digamos todo esto, el solo hecho de hablar de lo indígena se entendían un poco de cosas que eran, se salían digamos de la mentalidad que las familias vivían. Cuando empezaron a ver la articulación con pueblos, ya se vio que los abuelos antes, muchos abuelos por la mañana se paraban y se fumaban un tabaco, es que el abuelo se paraba en la chagra y se fumaba tabaco y volvía a desayunar. Entonces cuando llegaron los intercambios, la relación con los otros pueblos, entonces apareció el tabaco ya como una forma preferente en toda actividad, que los rituales, que las ceremonias, se empezó a escuchar que eran ceremonias de lo tradicional, que por qué se ofrendaba a la Madre Tierra para la siembra, entonces muchos mayores empezaron a entender y encontrarse en algo que 
sabían, sin entenderlo, pero que estaban haciendo. (Henry Neuta, 24 de agosto del 2012)

Para los miembros de la comunidad, saber que eran indígenas fue un momento crítico que motivó una serie de procesos en los que a las prácticas ancestrales ellos mismos les otorgaban sentidos de los que antes no eran conscientes y que poco a poco resurgían. Dicha tarea fue llevada a cabo sobre todo por generaciones jóvenes que afrontaron las coyunturas políticas de los años noventa.

Luego de ilustrar cómo se aplica el modelo performativo de Turner en las transformaciones del campo etnopolítico y de explicar su relación con el debate primordial-instrumental, paso a presentar varios relatos etnográficos en los que se evidencia la transicionalidad de la condición muisca.

\section{La aceptación de ser indígenas: ambivalencias en Cota y Bosa}

Tras la muerte de la abuela de Jimmy Fiquitiva, la primera semana de junio del 2012, Leonilde Balsero pasó a ser la persona más anciana de la comunidad muisca de Cota. Desde el momento en que me presenté en la oficina del cabildo y expresé mi intención de realizar trabajo de campo en la comunidad, el entonces gobernador Luis Calderón imperativamente indicó que había que entrevistar a esa "abuela". Canosa, de pelo largo trenzado, y siempre dispuesta a hacer algún oficio en su casa, Leonilde se mantiene lúcida y activa a pesar de su lento caminar. Ella comulga en su casa todos los domingos gracias a que el párroco la visita y allí mismo celebra el sacramento católico. La manera como nuestra conversación comenzó da pistas sobre la ambivalencia de las denominaciones indio, indígena, nativo y muisca empleadas por los comuneros de Cota.

Inicialmente, Leonilde afirmó su pertenencia a la comunidad no por la denominación, sino por la organización en torno al territorio: "Que pertenecemos, sí, al resguardo de la comunidad, mi papá era del resguardo y la mamá también”. Luego resaltó la condición étnica de su padre al decir: "Mi papá también era indígena de los puros 
antiguos y los padres también". Luego quise saber si ella misma, cuando era niña, sabía que era indígena, a lo que me respondió nuevamente haciendo referencia al territorio del resguardo y a la identidad, no de ella, sino de su esposo: "Ahí nombraban el monte, pero como nosotros éramos chiquitos y mi marido tuvo un pedazo de monte, ¿no? Un pedazo de monte grande, y como él murió, ahí quedó todo". Con sus respuestas noté que Leonilde no se identificaba nominalmente como indígena - por lo menos así fue en un primer momento-, entonces decidí preguntarle cómo lo hacía, y me respondió escueta y contundentemente: "Como persona de campo". Traté de emplear otra estrategia que consistió en indagar sobre sus memorias respecto a elementos culturales y organizativos considerados hoy en día como "propios" de las comunidades muiscas. Al nombrarle el uso o consumo del tabaco, me respondió con cierta apatía: "De eso sí no conozco". Opté entonces por saber algo acerca del cabildo, y su respuesta dejó ver los asuntos de género: "No, porque como uno son salía, el marido es el que va por allá. Él estaba por allá en las reuniones". Y al preguntarle simplemente qué le contaba su marido, respondió: "Yo no me acuerdo". Nuevamente cambié mi estrategia y empleé la asociación libre. Le pregunté: "Si le digo la palabra muisca, ¿qué le dice?". "Lo que les escucho a ellos, no me acuerdo", respondió Leonilde, nuevamente exteriorizando sus referentes mientras señalaba a su hijo Alfonso y al entonces gobernador Luis Calderón. Decidí seguir preguntándole por "los indígenas", en general. Leonilde comentó que no había muchas casas en el monte, que todos buscaban leña, que había una fiesta de Corpus Christi particular para los indígenas al igual que la celebración de Semana Santa. También me dijo que quienes eran pobres comían a las cinco de la tarde y que a las seis ya estaban en cama, pues no había nada con qué alumbrar la casa más que velas de cebo. Casi al final de nuestra tertulia, ella afirmó con vehemencia que su marido "era natural de Cota e indígena también" (el énfasis es mío). Insistí entonces en preguntarle si ella lo era, a lo que me respondió afirmativamente que era indígena al igual que su padre. Y remató con algo inesperado para mí, quien trataba de emplear la categoría indígena como la "políticamente correcta": 
Teníamos que ser, seguro. Ellos [sus papás] decían que eran indios. Nosotros semos puros indios indígenas, indios refinados [risas]. Me acordé de la palabra [risas]. Ricardo [su esposo] también decía que era indio refinado. Sí, ellos no decían indígenas, sino indios. (Leonilde Balsero, 15 de junio del 2012. El énfasis es mío)

Cierta ambivalencia pueden marcar las palabras indígena, indio, persona de campo, natural o nativo cuando se yuxtaponen. En el caso de Cota, como territorio rural, la denominación indio o indígena parece haberse mantenido libre de prejuicios, de ahí que su desuso no se deba a connotaciones peyorativas. Pese a que, como vimos en el capítulo anterior, algunos gobernadores indígenas optaban por entregarle tierra de resguardo a los “más feitos", para Jimmy Fiquitiva, actual beneficiario de una adjudicación en la falda del cerro Majuy, estas denominaciones son recurrentes en sus memorias. Me dijo que de niño sí escuchó la expresión "somos indígenas":

Sí se aceptaba y de hecho se aceptaba tanto que se saludaban "quiubo ole, indio", "quiubo, chivato", en fin, con esos términos que son vocablos muiscas. (Jimmy Fiquitiva, 15 de junio del 2012)

En otros casos, como en Suba y Bosa, la categoría indígena se negaba, pues la expansión geográfica de la ciudad y el modo de vida urbano fomentaron más exclusión y juicios peyorativos respecto al indio. Santiago Martínez Ojeda, en su etnografía sobre la relación entre identidad y curación en la comunidad muisca de Bosa (2009), registró cómo Beatriz Chiguasuque recordaba que la gente asociaba su apellido con la denominación chibcha ${ }^{33}$; "Por el apellido Chigua... Chiguas... Chigua ¿qué? Usted lo que es chibcha" (Martínez, 2009, p. 27. El énfasis es mío). Por su parte, Henry Neuta, mucho más joven que Beatriz, también tiene memorias sobre el ocultamiento de la denominación indígena

33 Chibcha es el nombre de la macrofamilia lingüística que agrupa varias lenguas indígenas en el territorio comprendido por lo que hoy es Costa Rica, Panamá, Colombia y el norte de Ecuador. Chibcha fue durante el siglo XIX y gran parte del xx la denominación para referirse a los muiscas, grupo étnico más representativo e importante. 
a través del término marmato y la reserva de indio como mecanismo lingüístico para el prejuicio y la exclusión:

Nos encontrábamos con mi abuelo, mi abuelo se encontraba con los amigos, iban a tomar cerveza, chicha, y entonces yo me acuerdo que ellos decían entonces, digamos mi mamá le preguntaba: “¿Quién es ese señor?”, entonces decía: “Ese es marmato”, entonces ya uno entendía que marmato era de aquí. "Son marmatos de acá". Es lo que referencio digamos yo de que escuchaba de si indios. Algunos señores utilizaban el cabello largo, a esos les decía: "Ese es un indio", pero de pronto despectivamente, yo creo, decía: "Ese es un indio". Yo me acuerdo de niño era así, a la edad de los ocho o diez años íbamos mucho los domingos a comer o a almorzar o a lo que fuera ahí en la plazoleta. Es como lo que yo me acuerdo hasta cierto momento que referenciaba esto de indígenas. (Henry Neuta, 24 de agosto del 2012)

La oscilación entre diferentes términos y denominaciones señala que, aunque las comunidades y sus familias habían mantenido ciertas categorías para establecer diferencias sociales, sea porque formaban parte del lenguaje cotidiano o debido a prejuicios del mundo exterior que repercutieron dentro de la comunidad, el contexto político y las circunstancias personales de los comuneros desde los años noventa obligaron a fortalecer la conciencia étnica y a asumirla con intensidad.

\section{Revelaciones en Suba: los tránsitos de Bárbara Bulla, su hija y su nieta}

Seguramente por el espacio íntimo y privado que se creó, la conversación que tuve con Dioselina y Myriam, madre e hija, de la comunidad de Suba, reveló cómo la aceptación de "ser indígena" es un tránsito difícil de asumir porque es transversal a sus propias crisis. En el caso de Dioselina, cuando el señor Carlos Caita comenzó a reunir a las familias para hablarles de "los indígenas de Suba", ella misma no lo creyó. Sin embargo, pensando en la meta de recuperar los terrenos que le habían sido usurpados a su madre, Dioselina formó parte de la primera 
organización indígena. Myriam, su hija, a través de sus memorias de juventud, describe cómo vivió ese tránsito.

[...] y para nosotros había sido un poco difícil entender eso. ¿Por qué fue tan difícil? Pues porque nos habían dicho que los muiscas habían existido. Cuando a mí me enseñaron en la escuela la historia, me habían dicho que era del pasado, yo no entendía muy bien eso y a mí al comienzo me daba mucha vergüenza y a mis hermanas les daba risa, nosotros nos reíamos pero nosotros acompañábamos a mi mamá [...] eran despectivos, porque digamos en el pensamiento el indígena es el que anda con taparrabo, esa es la visión y la gente no tiene la culpa, porque les enseñan que un indígena es con taparrabo y plumas. Entonces cuando lo miran a uno, lo miran con escepticismo porque no le ven los taparrabos. Tuve una vez que pelear en un escenario con una persona: "Qué pena con usted, yo soy muisca, yo soy de este territorio y así yo no use, ni mis ancestros usaron taparrabo", porque con ese frío tan verraco [tan intenso] que hace acá, nos tocaba con mantas y con ruanas, con iquiras [sic] ¿sí? y apenas quedó como... sí, es como decirle a un pasto ande con taparrabo. (Myriam Martínez Triviño, 9 de septiembre del 2011)

Dioselina, su madre, también tenía esos mismos prejuicios. La representación del indígena como una alteridad demasiado extraña, construida durante la Colonia y estrechamente asociada a la naturaleza también pesaba sobre sus pensamientos. Sin embargo, esas mismas representaciones se convirtieron en referentes fundamentales de identificación y de tránsito cuando pudo viajar a Mitú y conocer a las comunidades nativas en torno a la práctica del yagé.

Dí ese paso... para mí ser indígena, no sé, ponerse un taparrabo y plumas. Es lo que uno lleva, porque hace poquito fui a un ritual indígena, y a los años que tengo nunca pensé en ver algo tan lindo, porque todos reunidos con su indígena y tomando yagé y en una fiesta. Me siento feliz de que Diosito no me haya llevado sin conocer mi cultura tan hermosa que es para saber qué es lo espiritual y todo, todo. (Dioselina Triviño Bulla, 9 de septiembre del 2011. El énfasis es mío) 
Ella había dado "ese paso", había transitado de sus prejuicios a su identificación con la atmósfera espiritual que conlleva la representación de lo indígena yagecero ${ }^{34}$. Eso la llevó a relacionar más elementos de otros indígenas con las características culturales de su propia familia, la cual ella misma empezaba a identificarla muisca, pero no sin tener que superar varios obstáculos.

Myriam, por ser la hija mayor de tres hermanas, asumió una identificación plena; el lugar que ocupa está proporcionalmente relacionado con su nivel de compromiso y militancia, esto la llevó a ser joven líder, gobernadora e, incluso, a transitar por el mundo "espiritual". La hermana que le sigue, Adriana, en correspondencia con el lugar que ocupa, a veces oscila entre la identificación plena y la indiferencia. A propósito, en el Festival de la Luna Resplandeciente, llevado a cabo en el parque Mirador de los Nevados de Suba, organizado bajo la gobernación de su hermana mayor, aquella vez me decía que "le parecía muy interesante lo de ser muisca", sobre todo al ver los beneficios que eso traía a muchas familias. En ese momento, Adriana colaboraba en el proyecto Canasta Complementaria de Alimentos de la Secretaría Distrital de Integración Social, es decir, donde la organización indígena recibía mercados para donarlos a las familias menos favorecidas de la comunidad. Por su parte, Milena, la menor, aunque no niega la identidad étnica ni la pertenencia de su familia a la comunidad muisca de Suba, prefiere mantenerse alejada de esos asuntos. En suma, tres hermanas, un mismo núcleo familiar y tres diferentes formas de transitar y asumir la identidad étnica. Myriam, la más comprometida, recuerda ciertas revelaciones que tuvo de joven que incluso la llevaron a tener problemas con sus primos. De nuestra conversación esta vez emergían las representaciones de raza, y nuevamente una comunera encontraba las razones subyacentes a la negación de la identidad étnica en las construcciones simbólicas instauradas durante la Colonia.

Sí, porque digamos yo lo digo por mi familia, porque nosotros nos caracterizamos por tener un poco las facciones ancestrales. Yo tengo unos primos que incluso el color de la piel es más oscura,

34 Sobre este punto ahondaremos en el tercer capítulo. 
y ellos decían: "No, nosotros no somos indígenas”. Ellos no creían y le decían a mi mamá que estaba loca, porque mi mamá, como una de las líderes, le decían: "Eso, mi tía se volvió loca diciendo que es indígena”. Entonces digamos un poco que la gente no creía. ¿Por qué? Fue tan duro el proceso de colonización que tuvimos nosotros los muiscas y sobre todo el territorio de Bacatá, que digamos un indígena era lo peor, muy despectivo, era el sucio, el salvaje, el ignorante, el que no sabía nada. (Myriam Martínez Triviño, 24 de septiembre del 2011)

Pero para quien el tránsito fue muy difícil de asumir, según Dioselina, fue para su madre, Bárbara Bulla, pues no admitía la denominación indígena; no le era posible. La denominación que ella prefería, y que había usado toda su vida, no ocultaba las raíces de sus ancestros ni su relación con el territorio de Suba. Lo que parecía querer negar era el prejuicio que conlleva nuevamente el término. Así lo cuentan Dioselina y Myriam en su conversación.

Dioselina: Ella, mi mamá [Bárbara Bulla], no decía que era indígena, sino que era nativa: "Nosotros somos nativos, nosotros nacimos acá”. Sumercé, en eso de somos nativos, nada de somos indígenas, somos chibchas o muiscas, esas palabras no salían.

Myriam: No, nosotros no, cuando hablábamos del cabildo y decíamos que era indígena, ella me dijo: "Niña, nosotros no somos indígenas, somos nativos", ella siempre nos dijo que somos nativos y yo le decía: "Abuelita, pero ¿por qué dice que somos nativos?”, ella me decía que porque ella toda su vida la había vivido ahí, toda la familia, sus tíos, sus abuelos eran de ahí y que por eso éramos nativos del territorio, ella nunca dijo que indígenas y ella se molestaba y decía que nosotros no éramos indígenas, que éramos nativos. (Dioselina Triviño Bulla y Myriam Martínez Triviño, 9 de septiembre del 2011)

Pero la máxima revelación para Dioselina y Myriam respecto a su linaje indígena fue que en medio del proceso de recolección de escrituras y documentos jurídicos antiguos, en el marco de los pleitos por tierras, en la escritura del terreno entregado al abuelo de Dioselina, 
padre de Bárbara, se leía claramente: "Entregado al indio Juan Bulla" (el énfasis es mío). Esto despertó un orgullo familiar que Dioselina nunca antes había tenido. Saber que su abuelo era un "indio", lejos de molestarla, impulsó su proceso de reconocimiento étnico y su lucha como líder de la primera organización indígena de Suba. Tal como lo expuse líneas atrás, una vez que el convencimiento se da internamente, hay que tramitarlo hacia fuera:

Ahí me gustó el proceso, y cuando nosotros tuvimos la primera reunión ahí en la alcaldía, "no, que los indígenas de Suba”, eso fue un bombo saber que éramos, porque las instituciones decían que no habían en Bogotá y se pararon a mirarnos a ver cómo éramos, y yo con la pinta normal y nos preguntaron: “¿Ustedes cómo sienten lo indígena, cómo sienten la cultura?”, nos tocó muy duro porque las instituciones nos trataron duro, fue duro. (Dioselina Triviño Bulla, 9 de septiembre del 2011. El énfasis es mío)

Pero las mismas familias debían convencerse a sí mismas de su identidad étnica o hacerla consciente. Con la revelación de las escrituras del indio Juan Bulla y ante la cohesión que la identificación étnica generaba en las familias para luchar por sus tierras, Bárbara Bulla no tuvo más remedio que aceptar su linaje no solo nativo, sino indígena. Su hija y nieta afirman que para ella fue muy duro aceptarlo a sus casi 80 años de edad. Sin embargo, una vez que Dioselina le insistió sobre el tema, su madre asintió:

Después me fui a hablar con ella, después me dijo que "mija, yo creo que sí, porque toda la vida hemos vivido aquí, los ranchos, porque una vez un rancho se nos quemó porque un día los ratones se robaron los fósforos [...] como eran casas de bareque y todo eso [...] y como había calentado el sol, se prendió y se acabaron los dos ranchitos. (Dioselina Triviño Bulla, 9 de septiembre del 2011)

En el caso de Bárbara, aceptar la indigeneidad no vino por cuenta del "bombo" que había en Suba y Bosa en esos tiempos; esta condición la aceptó cuando vio que los wiwas de la Sierra Nevada de Santa Marta vivían en casas de bareque, iguales a las que una vez se incendiaron 
por culpa de los ratones. La indigeneidad le parecía venir del material de su casa en la juventud.

\section{La Casa Indígena de Cota y los pinos políticos de Alfonso Fonseca Balsero}

La asignación de funciones y calificativos en cuanto "esquemas de percepción, pensamiento y acción" (Bourdieu, 1989, p. 14) hallados en los relatos sobre la historia de la organización indígena muisca de Cota se presenta en textos investigativos. Gómez Ramos, al momento de su etnografía, recurre a Alfonso Fonseca Balsero como una de sus fuentes, cuya administración en la década de los ochenta no duda en considerar como beneficiosa para la comunidad (1998, p. 197), cada vez más fragmentada internamente y amenazada de ser acabada por agentes externos. El papel otorgado a Alfonso como "ordenador" de varios asuntos que históricamente habían afectado la organización indígena también es asumido por él mismo. Así, con su testimonio, compartiendo su propia versión y lectura de la comunidad, entra a formar parte del campo de poderes simbólicos. Para este estudio específico, Alfonso representa un caso ejemplar en lo relativo a la manera como la identidad étnica se activa y agencia en momentos críticos y coyunturales, sobre todo ante amenazas externas contra la comunidad.

Alfonso siempre se presentó ante mí como una persona que desde su época de juventud en el colegio había emprendido iniciativas de trabajo comunitario, principalmente de educación para familias pobres, inspirado por ideas de izquierda y revolucionarias transmitidas por uno de sus profesores. Eso le despertó el interés en conocer la historia del pueblo muisca; con fechas exactas y siempre teniendo en cuenta las acciones coercitivas de las autoridades coloniales y republicanas, particularmente las de la Iglesia católica. Por esa razón, las referencias a autoridades civiles y eclesiásticas están presentes en sus relatos de los enemigos a vencer. Cuando se le pregunta por sus aportes particulares al proceso organizativo de la comunidad muisca de Cota, sin dudar un instante elabora su respuesta, partiendo de la historia de cómo fue construida la Casa Indígena. 
Los Fonseca Balsero siempre vivieron en su casa, abajo, en el pueblo; no forman parte de las familias pobres que necesitaron que el cabildo les adjudicara un terreno en el resguardo. Esta suficiencia explica en cierta manera que en su forma de hablar se note cierto tono paternalista cuando de referirse sobre la comunidad se trata, lo que la hace ver a esta, por lo general, siempre vulnerable, fragmentada y, hasta cierto punto, débil, mientras que él proyecta su imagen de líder que aportó conocimientos y contactos políticos para favorecerla.

Y un día ya era secretario y necesitó la comunidad una reunión y le dijeron al cura a ver si les prestaba la casa cural para hacer una asamblea indígena, el cura dijo que no. Fueron y le dijeron al alcalde de turno y el alcalde dijo que no, porque se dañaban los instrumentos de música, que aquí había una banda. Y entonces ya estaba haciendo mis pinos políticos, y les dije: "Les voy a hacer una casa la verraca [excepcional], no sé en dónde pero la voy a hacer, aquí van a dejar de hacer reuniones debajo de los árboles o van a dejar de hacer reuniones pidiéndole cacao al maestro de la escuela, alcalde de turno, y menos a los curas". Y entonces seguí ya como secretario, entonces ya me incorporo a la comunidad. (Alfonso Fonseca Balsero, 22 de junio del 2012. El énfasis es mío)

Quiero resaltar dos aspectos de su relato. El primero, Alfonso afirma haberse "incorporado" a la comunidad. Con esto no podemos concluir tajantemente que él nunca se consideró indígena de Cota, sino hasta ese momento, pero sí queda claro que sus niveles de identificación comunitaria tienen correspondencia con el hecho de haber asumido papeles de poder en esta y, en cierta manera, que su expresión - el haberse incorporado- se concretó en tránsitos desde esferas casi exteriores o, por lo menos, con cierta distancia del núcleo de asuntos comunitarios. Precisamente, el segundo aspecto es que el acto de incorporarse a los asuntos comunitarios coincide con un tránsito político y administrativo que, en el caso de Alfonso, es concomitante con su papel como secretario del cabildo y aspirante a cargos políticos del pueblo.

Aunque se identificaba con ideas de izquierda en su juventud -Alfonso es liberal—, comentó que dentro de la comunidad indígena la familia Segura, a veces rival y a veces aliada de los Fonseca, siempre 
fue conservadora. Como en su momento el conservador Cristóbal Segura era el gobernador del cabildo, Alfonso inició un movimiento político al que llamó Unión Resguardo Indígena, con miras a tener una facción liberal indígena y que, de paso, fuera su plataforma política para aspirar a cargos políticos en Cota. Se presentó como candidato al Concejo municipal, pero no fue elegido. En 1986, se presentó nuevamente como candidato, esta vez con otro movimiento al que denominó Movimiento Cívico Popular de Cota, respaldado por el Partido Liberal Colombiano. Esta vez sí logró su objetivo y, como dice él mismo, "ya tenía sus cartas": era concejal, fue elegido gobernador del cabildo indígena al siguiente año (1987), era presidente de la Junta de Acción Comunal de su barrio e integraba el Directorio Nacional del Partido Liberal Colombiano. También dice con orgullo que siempre fue amigo de "los López Michelsen", familia de linaje presidencial en Colombia, y que se ganó la confianza de Ernesto Samper Pizano, expresidente de Colombia (1994-1998), quien en ese momento aspiraba a ser senador de la República. Alfonso movió “sus cartas” y le propuso a Samper Pizano que aportara parte de sus auxilios parlamentarios para la construcción de la Casa Indígena. Esto se logró gracias, entre otras cosas, a que el liderazgo de Alfonso en la comunidad indígena de Cota le representaba un buen capital simbólico para obtener un significativo número de votos.

Entonces él dijo que nos ayudaba a hacer la casa, que él ponía su equipo del poder popular a la casa con los aportes de los auxilios parlamentarios, y él cumplió, cumplió porque le dije: “Así como yo me subo a una tarima a decir 'voten por fulano', también soy capaz de subirme a decir 'no voten porque ese man es un tramposo, es un jodido"”, así se lo dije a Samper. (Alfonso Fonseca Balsero, 22 de junio del 2012)

Como concejal, Alfonso logró que Samper Pizano aportara 3500000 pesos, aun cuando el gobernador del cabildo, José Joaquín Fiquitiva, pensaba que usar un recurso del Gobierno para tal diligencia no era posible. Por ese motivo, tal inversión se vino a concretar en 1987, cuando Alfonso asumió la gobernación indígena. Pero, según cuenta, se encontró con un obstáculo jurídico-político que, también gracias a su 
creatividad e instrumentalización de sus cargos, logró superar. Resulta que en 1987, la normatividad colombiana no permitía que las comunidades indígenas, como si fuesen "menores de edad", recibieran dinero para ser administrado por ellas mismas. Ante este impedimento, la estrategia de Alfonso fue recurrir entonces a la Junta de Acción Comunal, figura reconocida estatalmente, que sí podía recibir tales recursos.

Como las Juntas de Acción Comunal estaban reconocidas por el Estado y sí podían manejar recursos, fui a la comunidad del Abra, les dije: “Aquí está la junta comunal”, también había un gran amigo, político, le dije: "Mijo, como somos samperistas hagamos esta figura: que el doctor Samper le gire a la Junta de Acción Comunal de la comunidad del Abra para construir en predios de la comunidad la casa de la comunidad indígena de Cota”. (Alfonso Fonseca Balsero, 22 de junio del 2012)

El lote de la casa se empezó a adquirir en 1984, cuando Alfonso lideró un proceso de toma del predio mediante siembra de árboles y colocación de piedras. Aunque el predio estaba a nombre de Vicente Ruiz, un "intocable de Cota", según Alfonso, se sabía que ese terreno había sido inicialmente del resguardo pero que se perdió durante la época de crisis y conflictos con las empresas mineras de explotación de canteras. Con todo y eso, los pleitos jurídicos terminaron a favor de la comunidad indígena. Para construir la casa, Alfonso impuso en el marco de su gobernación el trabajo social obligatorio para jóvenes que buscaban ser certificados por el cabildo y quedar exentos del servicio militar, como ya lo dictaminaba la ley en ese entonces.

La Casa Indígena de Cota fue construida durante el tiempo en que el país hizo la transición política marcada por la Constitución de 1991; su inauguración fue el 17 de enero de 1992. Alfonso concluye este relato recordando que aprendió de Cristóbal Segura y de "otros abuelos" cómo funcionaba la política estatal. Conoce perfectamente cada renglón de la Ley 89 de 1890, que reglamenta y defiende los territorios y comunidades indígenas, a pesar de que en un principio su objetivo era generar una plataforma para que estas transitaran hacia la vida capitalista y el dominio de la propiedad privada. En este punto es en el que Alfonso insiste en que conocer la política estatal y sus intrincados 
caminos, herencia del hombre blanco, es fundamental para poder encaminar los recursos jurídicos y administrativos modernos hacia el fortalecimiento de las comunidades como sujeto colectivo de derechos.

Porque nosotros ya habíamos pasado por todo ese proceso. Nosotros nos hemos es devuelto porque nosotros sabemos todo el proceso de la tenencia de la tierra desde un punto de vista particular, privado, y hemos ido hacia lo social. Hemos revitalizado y hemos ido a la inversa, nosotros tenemos todo lo de la sociedad mayoritaria, de toda la contaminación, en lengua, en muchas cosas. Ya sabemos cuáles son las respuestas, cuáles son las conductas de la gente. (Alfonso Fonseca Balsero, 22 de junio del 2012)

Las palabras de Alfonso son muy dicientes respecto a la manera como suelen ser interpretadas las comunidades indígenas frente a la sociedad mayoritaria, por lo general, como un claro rezago de la colonialidad: estas se han "contaminado" y todos sus problemas vienen de afuera. Entre los elementos contaminantes, resalta la concepción de la tierra como propiedad y mercancía. Este tipo de razones generan una ambigua relación con lo que los comuneros llaman "el pensamiento occidental", pues este los ha "contaminado" al tiempo que les ha brindado herramientas jurídicas para reivindicar su existencia y diferencia cultural. Como consecuencia, es habitual que los líderes indígenas afirmen que es importante conocer los "métodos de Occidente" y usarlos a su favor.

En los siguientes apartados analizaré la relación que existe entre la necesidad de demostrar la identidad étnica y la performancia de las comunidades para lograrlo. Como lo he argumentado a lo largo de este capítulo, la primera se activa de acuerdo al momento crítico vivido y, para ello, se despliegan varios dispositivos de tipo estético, administrativo y burocrático. A los casos de los cabildos estatalmente reconocidos se sumará la experiencia de la organización PNMC. La razón es que independientemente de las disputas que existen entre ambos tipos de organizaciones - las cuales son analizadas en el quinto capítulo-, las une el hecho de tener que pasar por rituales de tipo político-administrativo para su reconocimiento. La experiencia de los cabildos oficiales, además, nos permitirá comprender cómo las crisis que motivan la demostración de la condición étnica muchas veces las 
generan conflictos internos relacionados con el poder, que demuestran que los tránsitos hacia la identidad colectiva no se dan de la misma manera entre sus miembros. La experiencia de PNMC nos permitirá entender cómo el autorreconocimiento, en cuanto criterio subjetivo para definir la condición étnica, puede resultar eficazmente agenciado.

\section{“Qué nos inventamos?”: solidaridades y enemistades en Suba}

El 21 de septiembre del 2011, la comunidad muisca de Suba celebró la segunda versión del Festival de la Luna Resplandeciente. La novedosa festividad propuesta por Myriam Martínez Triviño durante su gobernación del cabildo reunió, en el equinoccio de otoño, a las familias de la comunidad, en el parque Mirador de los Nevados. Tenía como objetivo promover los lazos solidarios, brindar un espacio recreativo a las familias y transmitir algunas conclusiones que Myriam y su mamá habían compilado respecto a la naciente Política Pública Indígena de Bogotá, además de las experiencias de sus viajes a La Guajira para recibir la palabra de mamos de la Sierra Nevada de Santa Marta. A las siete de la mañana inició el evento con un pequeño ritual celebrado en una tarima, allí se congregaron en círculo las autoridades del cabildo mientras el abuelo Ignacio y la abuela Blanca Nieves saludaban al territorio y soplaban josca (tabaco en polvo) en las narices de ambos. El manejo del tabaco por parte de ambos era algo novedoso para varias de las personas presentes en el auditorio; más que elementos integrados a la ceremonia, las ofrendas de tabaco las veían con desconcierto, algunas personas incluso se persignaban. Luego la festividad tomó la apariencia de un bazar: música andina y tropical contemporánea se escuchaba a través de los parlantes dispuestos en la tarima; las familias se acomodaban en el prado mientras sus hijos corrían y jugaban, algunos niños vestidos con túnicas blancas bailaban y participaban en talleres de artesanías y tejidos; unas personas colaboraban actualizando los registros de las familias beneficiarias del programa Canasta Complementaria de Alimentos (mercados); otras hacían fila con boletas en mano para reclamar almuerzo y chicha, y un grupo interesado en los asuntos políticos y administrativos escuchaba a Myriam, 
quien se encontraba dictando una pequeña charla en el salón del aula ambiental, asignado para talleres y eventos educativos. La atmósfera del festival se caracterizó también por la repartición de afiches y panfletos de orden propagandista por doquier, tanto de Claudia Yopasá, quien en ese momento aspiraba a ser edilesa de Suba, formando parte del Polo Democrático - partido político de izquierda-, como de un comunero de apellido Neuque, candidato al Concejo de Bogotá y como miembro del Partido de la U — partido político de derechaLa jornada finalizó con una muestra artística a cargo del grupo musical Fuchunsua, cuyas fusiones de heavy metal con melodías andinas y cierto aire indígena deleitaron a varios asistentes, interpretando guitarras, bajo eléctrico, batería, zampoñas, quenas y sonajeros de semillas.

Reunir familias en torno a eventos similares es una práctica tradicional de esta comunidad indígena que cuenta con aproximadamente veinte años de reconocimiento oficial. Paralelamente a los procesos burocráticos relacionados con el reconocimiento como etnia para luchar por la tierra en Suba, la comunidad había creado grupos de jóvenes y consejos de mayores e implementado varios proyectos de recuperación de memoria, de los usos y de las costumbres, como la comida, medicina, danza, tejido y la lengua. En Suba ocurría lo mismo que comentaba Victoria Neuta, lideresa de Bosa; los apellidos y las relaciones vecinales-veredales de antaño fueron el primer eslabón de una cadena de vínculos de las familias con su pasado indígena, que, además, permitió el fortalecimiento de las relaciones comunitarias necesarias para presentarse como colectivo ante las instancias estatales que debían legitimar oficialmente su existencia como parcialidad indígena. Por esa razón, uno de los pasos para completar los documentos requeridos por la DGAI del Ministerio del Interior fue la elaboración de un censo. Dioselina Triviño cuenta que "pasaban de casa en casa" juntando escrituras, partidas de bautismo y registros civiles que permitieran fundamentar el linaje de cada persona y su historia en el territorio de Suba. Para pertenecer al cabildo, se había estipulado que la persona pudiera comprobar que era descendiente, máximo de la cuarta generación, de alguien cuyo terreno hubiese quedado escriturado a su nombre durante el repartimiento de 1888. Pero el estudio etnológico tendría un problema: como ya no hay resguardo en Suba, se dificultaba la labor de 
cualquier antropólogo o funcionario encargados de hacer un trabajo de campo permanente. Sin embargo, pese al mimetismo y a la atomización de las familias por los diferentes barrios de la actual localidad urbana, era obligatorio testificar los lazos comunitarios. Al igual que en el Festival de la Luna Resplandeciente, las lideresas entonces optaron por reunir a las familias en un potrero para que el antropólogo tuviera acceso a su campo.

Nosotros nos conocemos todos en el Rincón, en la vereda o barrio Rincón, los de allá de Tibabuyes se conocen todos, los del Salitre se conocen todas las familias [...] ya entonces en una de las reuniones que habíamos hecho nos encontramos las mismas familias, eran las mismas caras y llegaban: "Mire que el hijo de mi hija", entonces cuando el señor nos dijo que teníamos la reunión con el antropólogo, y llegaron tres señores, y de la alcaldía, mandaron también un revisor, y “¿cómo se van a reunir ustedes?”. Entonces nos reunimos la junta: “¿Qué nos inventamos?”. No, matamos una gallina en un asado, y don Pacho en un potrero grande, en una finca que tenía harto maíz, por un lado nos reunimos todas las familias. Eso fue grande la reunión, fue poner la olla y prepararon el asado, unos prepararon la carne; otros, la papa, y ellos fueron y miraron toda la gente. Se sentaban en grupos: “¿Usted de qué familia es? ¿Cuánto hace que vive aquí en Suba? ¿Usted cómo sabe que es indígena?". Pero pues como nosotros ya veníamos organizados, nosotros en las reuniones hacíamos los talleres, también con el trabajo de los abuelos, ya nos sentábamos con los abuelos y con los más viejos a hacerles averiguaciones de “¿cómo era el apellido, tío?” y así. Entonces así cogían los grupos de familias y así fue todo el día, eso fue desde la mañana porque eso arrancó desde las ocho de la mañana y hasta la noche, todo el día y llegaron e hicieron el estudio etnográfico. (Dioselina Triviño Bulla, 9 de septiembre del 2011. El énfasis es mío)

Finalmente, el Cabildo Muisca de Suba fue reconocido en el año 1991. Pero en el 2001, fruto de irregularidades en los censos de la comunidad llevados a cabo por uno de los más polémicos gobernadores, el cabildo indígena perdió su reconocimiento. Durante varios años, el fantasma 
de esta situación y de las acciones de este personaje se mantuvo en la memoria y en los asuntos cotidianos de la comunidad. El fantasma resurgió por un pleito de tierras en el que el exgobernador Roberto Galvis Bulla quiso reclamar un terreno de nombre el Charrascal, que había sido comprado por el urbanista Pedro Gómez a la empresa Bavaria, en 1974. Algunos simpatizantes de Galvis invadieron el terreno para instalarse en este. Como pruebas de su pertenencia, contaba con la escritura de 1888, la cual rebatió el abogado de Gómez, argumentando que la comunidad indígena no existía desde el 2001. A esto se sumaba el hecho de que Galvis se había atribuido a título personal la representación de la comunidad muisca de Suba, asunto que fue negado rotundamente por Myriam, la gobernadora de entonces. Para apelar la decisión desfavorable del Consejo de Estado, Galvis adjuntó el oficio mediante el cual la DGAI declaraba nuevamente la existencia de la comunidad indígena, en 2009 —después de realizar el mismo proceso de censo y estudio etnológico- Mientras tanto, varias personas de la comunidad afirmaron que detrás de las invasiones no había personas oficialmente reconocidas por la comunidad y que Roberto Galvis no era un representante legítimo de esta (Rico, 2010, enero 18).

Pero un esquema se repite a lo largo de la historia del Cabildo Muisca de Suba. Los gobernadores anteriores son cuestionados por nuevas generaciones y sus acciones son deslegitimadas. Mientras escribo estas líneas, Claudia Yopasá, quien no quedó como edilesa de la localidad, en 2011, ahora gobierna el cabildo indígena. Durante sus dos periodos de gobierno ha recriminado constantemente sobre los proyectos que su antecesora, Myriam, puso en práctica. Incluso el Festival de la Luna Resplandeciente dejó de celebrarse, y el abuelo Ignacio, quien en la apertura de su última versión ofreció tabaco, ha pensado seriamente quitar su consultorio de la sede del cabildo debido a los conflictos con la gobernadora. 


\section{Transferencias, crisis y estudio etnológico en Cota}

A partir de la década de los sesenta del siglo xx se impulsaron una serie de transformaciones estatales para darle cabida a una gran reforma agraria con la que se pretendió acabar con el latifundio, otorgar tierras a los campesinos y promover el desarrollo del campo ${ }^{35}$. Aunque la División de Asuntos Indígenas había ratificado en los setenta la existencia de las comunidades indígenas de Cota y Chía, sus tierras comunitarias eran identificadas por parte del Incora como "tierra indígena" o "comunidad indígena", pero no como resguardos. Esto obedecía a que, como vimos en el capítulo anterior, la compra y titulación colectiva de terrenos en el cerro Majuy en Cota y en las veredas de Fonquetá y Cerca de Piedra en Chía hacía que para muchos estas comunidades fueran consideradas como "civiles" y con alto grado de "aculturación" (Wiesner, 1988). Aun así, con las transformaciones políticas de 1991, las comunidades de Cota, Chía, Suba y Bosa fueron reconocidas como indígenas. El marco político, con la expedición de la Ley 60 de 1993, también reconoció a los cabildos como entidades autónomas y de carácter especial, mediante esta ley les dio el derecho de recibir recursos por parte del Estado o transferencias.

En el año de 1992, Alfonso Fonseca Balsero fue elegido alcalde del municipio de Cota, hecho que lo obligó a renunciar a la gobernación del cabildo indígena. En su nuevo cargo político municipal, a Alfonso le correspondió girarle los primeros 46 millones de pesos al cabildo indígena de su comunidad. Varios gobernadores, entre ellos José Fiquitiva y José María Cano, invirtieron parte de los recursos en la creación del jardín infantil y la escuela de la comunidad muisca. Cuando Alfonso terminó su periodo en la Alcaldía y quiso regresar como gobernador del cabildo, encontró que las transferencias estatales habían generado crisis

35 En ese marco y como parte de las políticas que regulaban la protección y disposición de tierras de resguardo y baldías, el Gobierno transformó la vieja Oficina de Asuntos Indígenas del Ministerio de Agricultura en una división especial del Ministerio de Gobierno de esa época. Con la expedición de la Ley 135 que le dio inicio a la reforma agraria, se creó el Incora. 
dentro de su comunidad. En su versión de los hechos, otros aspectos se suman a su caracterización presentada páginas atrás; adopta el papel de juez, de persona honesta y, hasta cierto punto, de víctima de aquellos que ambicionaban el poder para beneficio personal.

Yo termino mi alcaldía, en el 95 voy y les digo: "Bueno, yo quiero ser su gobernador para continuar el proyecto". Entonces ya había muchos intereses, como ya había plata todo mundo quería ser gobernador de la comunidad indígena y como de mí decían lo siguiente: "Ni roba ni deja robar", entonces "usted no, quite de aquí". Les dije: "Bueno, hasta lueguito, ahí los dejo y no quiero que la gallina de huevos de oro se les acabe”. Ya habían peleado con don Cristóbal Segura y a un grupo de nosotros que siempre hemos defendido el territorio nos sacaron. (Alfonso Fonseca Balsero, 22 de junio del 2012)

Las pugnas que diferentes líderes del cabildo sostenían con antiguos y permanentes gobernadores llevaron a que uno de los más representativos, Cristóbal Segura - a quien Alfonso se refiere como alguien a quien "sacaron" - enviara una comisión del Ministerio de Gobierno para que investigara las presuntas prácticas de corrupción por parte de quienes lideraban en su momento el cabildo. El viejo Cristóbal, por supuesto, tenía los contactos políticos para hacerlo. En ese momento los conflictos por el poder trascendieron a la comunidad indígena, razón por la cual esta quedó en peligro de ser considerada inexistente; un fantasma del pasado nuevamente aparecía.

Y como la comisión es para investigar, entonces comienzan a mirar cómo están los papeles de la comunidad, cómo estamos de papeles, mijo. Entonces, cédula real... dónde... ¿ ¿de dónde íbamos a sacar cédula real? [...] Entonces le dicen a la comunidad: “¿Dónde está la cédula real?, tráigala a ver”, a ver e históricamente no está y que no es el sitio, ¿'sí o no? Y no es el sitio, ese no es el resguardo. (Alfonso Fonseca Balsero, 22 de junio del 2012)

La solicitud de una cédula real colonial obedecía a coyunturas políticas; una estaba relacionada con las pugnas por el poder entre Cristóbal Segura y sus detractores en el cabildo indígena, otra correspondió a una 
serie de modificaciones que tuvo la Ley 35 de 1993, tras lo cual terminó siendo derogada en el 2001. Como su finalidad era reglamentar de manera más ortodoxa la distribución de los recursos de la nación, la normatividad del 2001 dictaminaba que para que una comunidad indígena fuera reconocida y, por lo tanto, tuviera el derecho de transferencias, debía cumplir con el requisito de tener un verdadero resguardo. Pero como lo expresó Alfonso, la comunidad de Cota no contaba con ninguna cédula real, ya que su resguardo era un terreno comprado y no uno entregado por las autoridades coloniales. Debido a que el Incora nunca realizó los estudios correspondientes al reconocimiento oficial del resguardo, la comunidad muisca de Cota dejó de recibir recursos estatales. El 24 de diciembre del 2001, por disposición del Comité Institucional de Pueblos indígenas, comunicada por el Departamento Nacional de Planeación al alcalde de Cota, se estableció que el resguardo no existía en el Incora (Correa Correa, 2002). A unos se les había acabado "la gallinita de los huevos de oro". A quienes se consideraban defensores de la comunidad, como Cristóbal, sus diligencias desembocaron en la negación de la existencia de esta. Alfonso asegura que Cristóbal conocía de antemano la resolución del Incora respecto al reconocimiento oficial del resguardo de Cota. En ambas facciones el orgullo personal estuvo por encima de los valores comunitarios. Estas pujas internas terminaron por darle la razón a los agentes externos que seguían viendo, como en tiempos tempranos de la República, al resguardo de Cota como obstáculo para el progreso.

Según Alfonso, a muchas personas siempre "les ha interesado la montaña" y para lograr su conquista han afirmado y defendido que es imposible recuperar "algo que estaba muerto" como la cultura muisca. Mientras tanto, los arrendamientos de tierras adjudicadas del resguardo por parte de familias comuneras continuaron. Eso fue considerado como el principal factor de conflictos dentro de la comunidad, pues unas facciones buscaban transformar significativamente la condición colectiva del resguardo y permitir que foráneos tuvieran acceso a la tierra mientras se beneficiaban económicamente.

La inexistencia del Cabildo Muisca de Cota fue declarada en el 2001, en el gobierno de Julio Balsero. En el 2004, Alfonso asume la gobernación y comienza a organizar un estudio etnológico de manera 
autónoma y sin mucho conocimiento en razón a la posibilidad de que la Alcaldía de Cota declarara el resguardo como bien de utilidad pública dispuesto para su expropiación, venta y titulaciones privadas. Las acciones de Alfonso para evitarlo fueron varias. Primero indagó a través de Google cómo hacer un estudio etnológico. Ya había aplicado su creatividad en asuntos del resguardo un decenio atrás, cuando tomó un diccionario y transformó los nombres de los predios en vocablos de lengua muisca. Luego agrupó las familias por apellidos y las denominó "clanes familiares", finalmente, implementó la identificación de los comuneros mediante lo que llamó la "cédula indígena". El cabildo seguía posesionándose anualmente como lo disponía la Ley 89 de 1890, pero no ante la alcaldía municipal como era costumbre. Con todo y esto, la comunidad, liderada por Alfonso, aún gozaba de cierto nivel de autodeterminación, por lo menos simbólica, es decir, según como él lo entiende, esta colectividad todavía contaba con la posibilidad de tener conciencia de una existencia previa a la nación colombiana y de su derecho a conservar y ejercer su plena autonomía y autogobierno, así siga formando parte del Estado ${ }^{36}$.

Entonces me subí a la gobernación indígena sin reconocimiento de nada ni nada. Entonces, ¿que cómo organizo la gente? Clanes familiares, me inventé la palabra clanes familiares. Entonces reunía a los Cano, otro domingo a los Tibaquicha, otro día a los Fiquitiva, otro día a los Neuque, otro día a los Balsero, eso era todo mundo feliz. Un censo, yo me inventé un censo, hice un formato superbacano, “árbol genealógico" lo llamé. Estudio bueno o malo pero cuando no hay plata acá uno se defiende con las muelas. Y bueno, dije: "Ahora necesito generar identidad". Me inventé la cédula indígena. Bueno, a esto hay que ponerle muelas, nosotros seguíamos como si estuviéramos reconocidos por el Gobierno. Ya no nos posesionaba la alcaldía, pero nosotros sí hicimos nuestra junta,

36 Sobre el tema de la autodeterminación (self-determination), recomiendo la lectura de estudios sobre casos representativos a nivel mundial, como el de Cataluña (Guibernau, 1997), Escocia (McCormick y Alexander), Quebec (Keating, 1997) y las Primeras Naciones en los Estados Unidos (Wilmer, 1997). 
nos nombramos y sigue aquí, eso aquí sigue la comunidad indígena. Porque yo sí decía: "Fuimos primero que Colombia”. A Colombia se la inventaron un poco de facinerosos, nosotros no somos invento. Entonces comencé a hacer la cédula, puse bandera, puse escudo, le puse un logotipo, ya seria a la cosa. Y nuevamente normas de emergencia, de facto, incluso si existe Malta, si existe el Vaticano, si existe un poco de naciones pequeñas. Entonces comienzo a organizar la gente, vamos es a organizarnos y a renacer con nuestra comunidad. (Alfonso Fonseca Balsero, 22 de junio del 2012)

Alfonso recuerda que al consultar en la municipalidad sobre la disolución del resguardo, mediante votación, sobresalen algunos apellidos de personas de la comunidad que votaron a favor, como Segura y Guitarrero; otros, en su defensa, como Tibaquicha y Tauta. Además, por su parte, el alcalde afirmaba vehementemente que en Cota "no había indios", su razón principal era la inexistencia de la lengua muisca, cuestión que motivó a Alfonso a profundizar en su estudio. Ante la posible disolución del resguardo hubo protestas y manifestaciones públicas a las que se sumaron otros pueblos indígenas y la ONIC (Organización Nacional de Indígenas de Colombia). De manera que el alcalde de Cota, Luis Eduardo Castro, terminó derogando el acuerdo.

Por medio de la gestión adminstrativa de un comunero de Cota que tenía una curul en la CAR, Alfonso logró conseguir recursos de esta entidad para financiar parte del estudio etnológico de las comunidades de Cota, Chía y Sesquilé, dado que estas también habían perdido su reconocimiento oficial como parcialidades indígenas en el 2001. Dicho estudio fue realizado por la Fundación Hemera bajo la dirección del antropólogo François Correa. El investigador, reconocido en las comunidades por uno de sus libros sobre la ideología solar muisca (Correa Rubio, 2004), dio un concepto favorable y, además, le imprimió a su informe un enfoque crítico al referirse a la "ausencia de una política pública del reconocimiento del Estado”, demostrando así que tales reconocimientos se tratan de "decisiones puntuales que una $\mathrm{u}$ otra administración va tomando según su percepción particular de las aspiraciones sociales, políticas y culturales de los pueblos o del movimiento indígena y social" (Fundación Hemera, 2006, p. 1). El equipo 
de antropólogos y abogados que trabajaron durante cuatro meses tuvieron en cuenta como punto de partida para el reconocimiento étnico el criterio subjetivo de la "autoidentificación” (pp. 2-3). Este estudio etnológico reconoce una distinción cultural y social muisca "que no deja duda de su identidad como indígenas" (p. 3). Los criterios que fundamentan la decisión fueron: en primer lugar, que los comuneros tienen conciencia de su identidad, han determinado mantenerla y decidido promoverla; en segundo lugar, que dicha conciencia no solo se manifiesta en su enunciación, sino además en tradiciones y valores socioculturales, y en tercer lugar, que han mantenido un territorio como ámbito de actividades colectivas de reproducción económica, social y cultural, teniendo en cuenta que se enmarca en una forma diferente de ser indígenas — urbana y contemporánea- que no responde a los estereotipos (p. 6). Todo lo anterior alude a la agencia del Cabildo Muisca de Cota y de los demás cabildos de Cundinamarca, gracias a la cual han logrado mantener su existencia a medida que se adaptan conforme se transforma su aparataje de fortalecimiento institucional y cultural, todo un proceso además atravesado por etapas críticas y por rituales de índole jurídica y política.

\section{Chía: entre el reconocimiento étnico y el de su territorio}

Pedro Socha, gobernador del cabildo de Chía en 1993, considera, al igual que Alfonso Fonseca Balsero, que su gestión le otorga el papel de ordenador y que su mandato le demanda imponer drásticamente la disciplina. Según Pedro, el principal problema de su comunidad son las acciones particulares que atentan contra los principios corporativos. En este caso, y en el marco político de los noventa que reglamentó la distribución de recursos de la nación, lo que se esperaba del Incora era el reconocimiento del resguardo, no con el fin de declarar la existencia de una comunidad indígena y tener derecho a las transferencias, sino con miras a que la propiedad titulada colectivamente adquiriera un estatus más adecuado y así evitar su constante saqueo y mercadeo. El ritual jurídico administrativo respondía a la necesidad de transformar el estatus de las tierras del resguardo, que se mantenía como 
simple propiedad colectiva y, por ende, definía a la comunidad como civil y no como étnica. Con ello, desde el punto de vista de Pedro Socha, habría una solución a la larga cadena de incidentes históricos que han afectado a su comunidad. En otras palabras, Pedro conecta los conflictos de tierras del presente con las imposiciones de órdenes territoriales desde la Colonia.

El proceso de legalización debemos hacerlo y que se titule en el Incora ese territorio como resguardo, porque siempre se ha manejado como territorio común. La lucha más grande es esa, que mantengamos ese territorio incólume, porque se ha luchado desde la Colonia, se ha luchado por todos los medios, los gobiernos, las alcaldías, en épocas anteriores, para que desaparezca esto y poder venderlo, hacer escrituras y que se llene esto de grandes mansiones, y fincas, y sacar de allí a todos los pobres. No es nuestra meta y por eso estamos luchando tanto, para que ese territorio permanezca incólume. Es la principal causa. A nosotros no nos trasnochan, sinceramente, las transferencias, eso lo hemos dicho al Ministerio del Interior, que ya toque por ley que las den, que son recursos y transferencias de la nación que está aprobado por ley, tampoco se puede rechazar, pero sí es el momento que nos reconozcan nuestro resguardo y nos lo titulen. Así nos digan: "No les vamos a dar transferencias", no es óbice para que nosotros lo aceptáramos a ojo cerrado. (Correa Correa, 2002)

Según una certificación expedida por la Secretaría de Hacienda del Municipio de Chía el 29 de enero de 1997, el predio del resguardo aparece identificado con el número catastral 00-00-0002-0572-000 y rotulado como "Cerro de la Comunidad". Pero, conforme a lo expuesto, la meta es que se distinga como resguardo indígena, incluso es importante para los comuneros la denominación misma. El objetivo era tan claro para el cabildo que el reconocimiento oficial como etnia por parte de la DGAI no importaba tanto como sí el expedido por el Incora respecto al resguardo. Si se piensa, su postura tenía correspondencia con la afirmación del investigador François Correa en el informe de la Fundación Hemera (2006) de que los reconocimientos étnicos estatales parecían estar determinados por circunstancias particulares y el libre 
criterio burocrático de las instituciones. Pero más allá de este informe, esta vez era la comunidad quien, como mecanismo de adaptación a los trámites administrativos, pretendía elegir o darle prioridad a uno u otro ritual jurídico. Como lo dejó claro Pedro Socha, más que el reconocimiento étnico, les interesaba el reconocimiento de su territorio como resguardo indígena.

El 5 de octubre de 1999, el director encargado de la DGAI, José Alfredo Escobar Araujo, expidió una certificación en la que esa dependencia del Ministerio del Interior reconoció la existencia de las comunidades indígenas de Fonquetá y Cerca de Piedra en el municipio de Chía, y además afirmó que "los Muiskas” reconocidos eran los del resguardo de Cota (Cundinamarca), del Cabildo de Fonquetá (Chía) y del Cabildo de Suba (Correa Correa, 2002). Bosa estaba a punto de obtener tal certificado. Por esa razón, el cabildo muisca de Chía radicó un oficio a la directora de la DGAI de ese entonces, manifestando que no había solicitado "reconocimiento a esa dirección ni a ninguna entidad, pues no se trata de una asociación o corporación que requiera para su existencia del reconocimiento del Estado", argumentando, además, que la existencia de la comunidad era un hecho social notorio que no requería demostración y que la calidad de indígena era algo que tampoco se adquiría mediante acto administrativo. A propósito, aclararon que, interesados en resolver los asuntos de tierras, habían solicitado gestionar ante el Incora el reconocimiento o la constitución del resguardo (Correa Correa, 2002).

Aunque fue a partir del año 2000 que se radicaron los documentos para iniciar el trámite del Incora, es importante recordar que, en el 2003, el Incora se convirtió en el Incoder. Después de muchos esfuerzos y conflictos, esta entidad no fue lo suficientemente diligente con el trámite, y eso tuvo consecuencias que afectaron en gran medida a los comuneros. Como ejemplo de ello y del despliegue del aparataje administrativo y político de reconocimiento y defensa de la identidad étnica, se halló un pleito por tierras y el derecho a la vivienda digna, que resultó en una acción de tutela (Corte Constitucional, Sentencia T-952 de 2010). También fueron evidentes los itinerarios burocráticos que los comuneros debían cursar institucionalmente para apelar tanto a su identidad indígena como a sus identidades civiles. 
La señora Lastenia Socha y su hijo Jerónimo, de la comunidad muisca de Cota, recibieron una adjudicación de tierra del resguardo, certificada el 3 de enero del 2010. En marzo de ese mismo año, Jerónimo y su madre fueron autorizados por el cabildo para construir su casa después de haber cumplido con los requerimientos internos. En ese mismo mes, la Gerencia de Planeación y Evaluación Integral de Chía citó a los comuneros del pleito para informarles de una apertura de investigación preliminar relacionada con irregularidades en la licencia y las normas urbanísticas de construcción, ya que, según el estamento, la edificación de la casa se haría en zona de alto riesgo por remoción. Doña Lastenia y su hijo presentaron descargos en una inspección de policía, y allí mismo se les informó que la Gerencia de Planeación había mandado suspender la obra. Radicaron entonces un derecho de petición ante la Alcaldía Municipal de Chía y se ordenó que la Gerencia de Planeación y Evaluación Integral de Chía estudiara en profundidad el caso. La acción de tutela se sustentaba, además, en el hecho de que doña Lastenia y su hijo habían perdido mucho dinero por la detención de su obra, ya que eso los obligaba a seguir pagando arriendo en un barrio del municipio.

La respuesta de la Gerencia de Planeación y Evaluación Integral al derecho de petición se refirió al estatus ambiguo del resguardo indígena; según esta institución, el resguardo no estaba registrado en el documento Conpes 131 sobre la Aesgpri (Asignación Especial del Sistema General de Participaciones para Resguardos Indígenas). No estar incluido en este listado convertía al resguardo en otro tipo de propiedad civil y lo obligaba a ser administrado mediante la jurisdicción regular y no mediante la jurisdicción indígena. En consecuencia, la facultad para determinar si había o no riesgo en la construcción o cualquier otra irregularidad la tendría el рот (Plan de Ordenamiento Territorial) de la municipalidad y no el cabildo en su plena autonomía. Ante la pregunta del despacho sobre la normatividad por la cual la Gerencia de Planeación estaría interviniendo en un territorio indígena, esta reiteró contundentemente que lo que existía era una "comunidad indígena", pero no un "resguardo indígena".

Las diferentes sentencias de esta tutela también dejan ver la interpretación particular tanto de la norma como de los factores que 
determinan la pertenencia étnica. La primera sentencia, emitida por el Juzgado Tercero Civil Municipal de Chía, favoreció a los comuneros indígenas, pues su identidad muisca no los obligaba a regirse bajo las normas regulares para esos casos, mientras que la segunda sentencia, por parte del Juzgado Segundo Civil de Zipaquirá, revocó la anterior y sustentó, además de la obligación del cabildo indígena de seguir los parámetros del РОт, que los “indígenas accionantes" no residían inicialmente en el territorio de su comunidad, sino en el pueblo, por lo cual la suspensión de la obra no significaba grandes traumatismos para esta.

El concepto final de la sentencia de la tutela determinó que, de acuerdo al material probatorio presentado, particularmente la constancia del Ministerio del Interior y de Justicia, se constata la existencia de la comunidad indígena de Chía pero no de su resguardo. La categoría de resguardo dependía de un trámite que inició el cabildo ante este ministerio, y mientras no se diera su aprobación, las tierras comunales corresponderían a una titulación colectiva a una comunidad civil. El primer fallo, por lo tanto, había desconocido la diferencia entre los conceptos comunidad indígena y resguardo. Así, el afán de Pedro Socha de conseguir el reconocimiento del resguardo quedaba nuevamente justificado. Por su parte, el abuelo Manuel Socha me comentó que la razón verdadera que motivó el pleito presentado era que los nuevos propietarios de un lujoso condominio, vecino al resguardo, habían "movido todas sus influencias" para evitar una construcción que, según ellos, "les dañaba el paisaje y desvalorizaba los predios".

\section{El fantasma del "no es resguardo" aparece en Cota}

El viernes 15 de noviembre del 2012, llegué a la Casa Indígena, sede del Cabildo Muisca de Cota, para encontrarme con el entonces gobernador Luis Calderón. Al llegar a la entrada del predio, no alcancé a bajarme del carro cuando me pidió el favor de que nos dirigiéramos a la vereda el Setime para recoger a quienes estaban midiendo el área total del resguardo. Pocos días antes, y tras varias diligencias y conflictos con funcionarios públicos, a quienes el gobernador se vio en la necesidad de encarar, el Incoder había autorizado la medición 
de las tierras con el fin de reconocerlo oficialmente como resguardo indígena. Cuando nos encontramos con el topógrafo de la institución y su acompañante de la comunidad muisca de Cota, corroboramos que la medición, que llevaba tres días de concluida, se había llevado a cabo rápidamente y sin problemas en lo que respectaba a la frontera occidental que se traza sobre la cuchilla del cerro Majuy. Pero otra era la situación con relación a la frontera oriental, pues fue trazada accidental e interrumpidamente sobre el piedemonte que comparten el resguardo y los predios privados de la parte plana que va hacia el pueblo. La razón era contundente. Por años, varias de las adjudicaciones de terrenos del resguardo a familias - sobre todo las menos favorecidas de la comunidad - fueron escrituradas como títulos privados por medio de triquiñuelas de foráneos y empresas constructoras que lograron convencer a varias familias comuneras de vender sus predios para beneficiarse económicamente. En varios casos, según Luis, había que entablar pleitos jurídicos, pues los procesos de escrituración y venta habían involucrado corrupción y clientelismo entre notarios, jueces, curadores, empresarios y comuneros. En otras palabras, si los repartimientos de los resguardos indígenas venían siendo la "piedra angular" del proyecto modernizador de la nación a partir de 1830 (Curry, 1981, p. 115), estos también representaban una piedra en el zapato para aquellos comuneros que veían en la identidad étnica un obstáculo para su propio progreso.

De regreso en la Casa Indígena, Luis Calderón se sentó en su escritorio y tomó una hoja de papel y un lápiz y elaboró una cartografía cuyos trazos no solo permitían ubicar geográficamente a cualquiera de sus interlocutores, también desplegaban rutas y sentidos que conectaban a Luis con su memoria histórica, incluso con la emotividad característica de quien recuerda todas las luchas acumuladas por él y sus ancestros.

Resulta que este es el municipio de Cota, aquí está el cerro del Majuy [los ubica en la hoja]. Entonces qué pasó, el resguardo colonial lo liquidaron en 1854, 58 [1858]. Entonces a cada indígena le daban de acuerdo, si por ejemplo tenía cinco hijos, le daban cinco derechos, que yo no sé cuánto debía ser el derecho, debía ser por 
ahí una fanegada. Entonces repartieron, repartieron, repartieron, ¿qué quedó? Lo del pueblo y lo del cerro [traza una línea divisoria que define un territorio plano y otro de montaña]. Entonces esto [el cerro] no se lo dieron a los indígenas, se lo dieron a la escuela como rentas de la Escuela de Varones de Cota. Un pueblo de cuatro casas, qué iba a tener plata. Ya vino aquí en el año de 1876, la escuela remata este terreno y es cuando se da lo de Pío León, Roque Capador y Vicente Tovar. (Luis Calderón, 15 de noviembre del 2012)

El fragmento anterior concluye con una oración que nombra de manera indirecta un hecho que Luis y los miembros de la comunidad conocen tan bien que lo han apropiado, por lo mismo lo da por evidente cuando dice "lo de Pío León, Roque Capador y Vicente Tovar". Exactamente hace referencia a la historia fundacional de los patriarcas de la comunidad muisca de Cota. Los tres fueron quienes lideraron el proceso de compra del terreno que conforma el resguardo hoy. Como era su interlocutor, se me ocurrió preguntarle — como quien no da nada por sentado, de hecho- si aquellos personajes formaban parte de la comunidad indígena de ese entonces. La respuesta de Luis desplegó una ruta de sentido marcada por otras preguntas movidas por la rabia y la frustración que conlleva el campo de las luchas indígenas en los marcos burocrático y jurídico.

Algunos dicen que eran como comisionistas y ¿por qué? Porque imagínese que todavía somos menores de edad hoy día, ¿`sí sabía eso? Somos menores de edad, 2012 y somos menores de edad. (Luis Calderón, 15 de noviembre del 2012)

Con su respuesta, que denota sarcasmo, Luis revelaba el fantasma de la minoría de edad, una condición impuesta al indígena hasta que la Constitución Política de 1991 reconoció la multiculturalidad y plurietnicidad de la nación y, por consiguiente, el derecho a la autonomía de las comunidades indígenas. En fin, la demora del Incoder en aprobar la medición del resguardo significaba para Luis una estratagema sutil del Estado para bloquear por medio de la burocracia lo que la jurisprudencia obligaba. Concluyó su cartografía en el papel, 
reiterando lo que los agrimensores ya habían expresado: las fronteras del norte (hacienda El Noviciado), del occidente (cuchilla del Majuy) y del sur (hacienda La Gioconda) habían sido trazadas sin problema por el Incoder; el problema estaba en la parte plana del piedemonte, la tierra más apetecida y valorizada. La comunidad de Cota tiene su resguardo en un terreno poco fértil, montaña arriba que nadie quiso, pero los conflictos se daban por la tenencia de las mejores tierras en la parte plana. Incluso Luis imaginaba que a los "indígenas con más plata” les habían vendido más tierras en aquel tiempo cuando inició la adquisición del terreno colectivo y que a partir de ese momento se desencadenaron los pleitos que han caracterizado el campo organizativo de la comunidad. La historia del resguardo de Cota, desde tiempos coloniales hasta los recientes, parece estar marcada por la sospecha y la certeza de que tanto personas externas como comuneros han podido ejercer su poder sobre la comunidad indígena, recurriendo a engaños, trampas y maniobras para quebrantar la ley y causar perjuicios a la comunidad misma.

Pero lo cierto es que las comunidades muiscas de Cundinamarca ansían que sus territorios transiten de la categoría de compras colectivas a la de resguardos. Mientras escribía estas líneas y corroboraba cierta información aplicada en la argumentación, el Incoder había anunciado, a través de su página web, en la edición de noticias del 12 de noviembre de 2012, que el Ministerio de Agricultura y Desarrollo Rural, junto con el Consejo Directivo del Incoder, había aprobado varios proyectos que beneficiarían a las comunidades indígenas de Colombia. La lista de proyectos iniciaba así: "Se constituirá el Resguardo Indígena Muisca de Fonquetá y Cerca de Piedra, en el municipio de Chía, Cundinamarca” (Acuerdo 315 de 2013). Se trataba de una buena noticia para la comunidad, que a la vez seguía demostrando que la identidad étnica y la organización indígena son asuntos de tránsitos en los planos burocrático y jurídico estatal. 


\section{Pueblo Nación Muisca Chibcha: el desafío al oficialismo ${ }^{37}$}

Sigifredo y Rodrigo Niño Rocha son hermanos que, a diferencia de sus otros dos, se autorreconocen como indígenas muiscas, identificación que les implicó, entre otras cosas, encontrar elementos culturales y valores de vida indígena en medio de la condición campesina de sus abuelos, quienes los criaron durante su niñez, siguiendo una tradición cundiboyacense. Ambos transitaron por prácticas gnósticas e indigenistas, las cuales solían retroalimentarse mutuamente en los años setenta. En 1976, en un encuentro celebrado en una vereda de Chiquinquirá, departamento de Boyacá, y presidido por integrantes de algunos movimientos indígenas en pleno furor y simpatizantes indigenistas, entre ellos los dos hermanos, surgió la idea de recuperar la antigua nación muisca. Esta idea se convirtió en el móvil para que cada hermano por su lado viajara a otros países y regiones. Así, conocieron personas de pueblos indígenas que vivían procesos de recuperación y fortalecimiento cultural, y fueron iniciados en prácticas medicinales y espirituales indígenas. Sigifredo se instaló en Bogotá y Rodrigo en Tunja. Sin embargo, continuaron con sus itinerarios, a través de los cuales encontraron personas que, según ellos, "andaban en el mismo rollo". Establecieron contactos y crearon redes sociales que les permitieron poco a poco configurar un liderazgo y grupos de seguidores. Al mismo tiempo, transitaron por estudios académicos y comenzaron a incursionar en el campo de la gestión cultural en torno a temas de recuperación de lengua, patrimonio, medicina y otros elementos de la cultura muisca. Tuvieron contactos y llegaron a establecer en su momento grupos de trabajo con gobernadores de algunos cabildos muiscas reconocidos, como Cota y Suba e, incluso, de otros pueblos, como los u'was.

Con el boom de lo indígena durante la década de los noventa y la primera del siglo XxI, y mediante su participación y manejo de escenarios de encuentro intercultural indígena - como los llevados a cabo en la maloca del Jardín Botánico de Bogotá José Celestino Mutis, desde

37 Las ideas introductorias sobre PNMC son tomadas de mi primer trabajo etnográfico con esta organización (Gómez Montañez, 2009). 
el año 2006 hasta el 2010—, Sigifredo y Rodrigo fortalecieron una organización denominada inicialmente Nación Muisca Chibcha, que con el tiempo se transformó en PNMC. La organización se declaró comunidad indígena por neto autorreconocimiento, lo que significaba que sus integrantes, aunque podían tener o no descendencia muisca comprobada, podían apelar a su conciencia individual, identificarse como indígenas y pertenecer a esta comunidad no reconocida estatalmente, la cual con el tiempo modificó y fortaleció sus criterios de membresía y ritualidades internas (Gómez Montañez, 2009). La historia de PNMC está atravesada tanto por redes de colaboración como por relaciones altamente conflictivas con los cabildos muiscas oficiales y también dentro de la misma organización. Cuando se esculca el pasado de estas redes, se encuentra que Sigifredo y Rodrigo trabajaron en conjunto con gobernadores muiscas en algún momento y que, años después, otras generaciones de líderes han juzgado gravemente sus incursiones en las comunidades; han llegado incluso a deslegitimar los pactos, alianzas y prácticas de los anteriores gobernadores. Este campo conflictivo se analizará profundamente en el quinto capítulo. Por ahora vale hacer una brevísima introducción sobre la manera como PNMC ha logrado también valerse de las herramientas jurídicas y políticas para legitimar su existencia como etnia, desafiando así el oficialismo tanto estatal como el derivado de los cabildos muiscas reconocidos.

PNMC, bajo el liderazgo de los hermanos Niño, está formada por dos cabildos mayores: el de Bacatá (Bogotá, agrupando personas de Cundinamarca) y el de Chunza (agrupando personas de Boyacá). Aunque en un principio, cuando comencé mi trabajo con estos cabildos, afirmaban no tener la intención de ser reconocidos oficialmente por el ministerio público ni de consolidarse como un proyecto indígena alternativo, a partir del año 2008 ambos emprendieron un camino de trámites para posesionarse anualmente ante las alcaldías respectivas, como lo dicta la Ley 89 de 1890. El caso del Cabildo Mayor Muisca de Bacatá de PNMC nunca se ha logrado concretar ante instancias oficiales, mientras que el Cabildo Mayor de Chunza de PNMC se ha posesionado ante la Alcaldía de Tunja desde el año 2010. Comprendamos cómo ha sido su itinerario para ello. 
Rodrigo Niño cursó estudios de antropología y derecho. Desde hace varios años vive en una casa muy humilde del barrio los Cojines del Zaque, a media cuadra del reducto del sitio arqueológico conocido desde la Colonia como Cojines del Diablo y que Rodrigo ha resignificado como Xue Puyquy 'Corazón del Sol', nombre que se puede leer en una placa a la entrada del parque, en la que también aparece el logo de PNMC para señalar la colaboración de la organización en la recuperación del sitio. En la sala de su casa hay una biblioteca en la que sobresalen todos los volúmenes de la obra de fray Pedro Simón, uno de los más importantes y representativos cronistas del Nuevo Reino de Granada. Rodrigo ha leído al detalle mis libros y es un excelente interlocutor en temas académicos; su discurso oral suele nutrirse bastante de lo que ha consultado en fuentes históricas y registrado en sus trabajos de acompañamiento a investigadores de la Academia Boyacense de Historia y arqueólogos de la UPTC (Universidad Pedagógica y Tecnológica de Colombia) de Tunja. Asimismo, sus estudios en derecho también han influido profundamente en su discurso escrito. Juiciosamente guarda un archivo que recoge toda la historia de su cabildo en Tunja, conformado en su mayoría por comunicados, actas, solicitudes, decretos y certificaciones de tipo jurídico y político; tiene una compulsión muy particular a dejar por escrito cualquier acuerdo, trivial o sustancial, al que haya llegado con otro cabildo o institución estatal. Además, siempre pide certificados de participación de cualquier evento al que asiste, en los que a veces figura como "señor", otras veces como "autoridad ancestral" y otras como "gobernador". Eso sí, su nombre "cristiano" (de pila) o "de la cédula", como él dice, aparece en casos en los que su firma es necesaria, pero siempre en renglón aparte junto con su nombre de chyquy: Xieguazinsa Ingativa Neusa. El lenguaje jurídico es tan importante para él que cada vez que escribe un comunicado que exprese la voluntad de su cabildo suele estructurarlo como un documento legal.

El archivo facilitado por Rodrigo Niño registra mediante documentos formales cada compromiso de su agenda como gobernador de un cabildo mayor que surgió para desafiar el campo etnopolítico muisca que ya se había fortalecido con la presencia y acción políticosocial de los cinco cabildos de Bogotá y Cundinamarca. PNMC no 
es una comunidad avalada por el Estado colombiano, pero, aun así, sus líderes han encontrado otros mecanismos para legitimar su existencia e historia como organización, según ellos, no indigenista, sino indígena muisca. Uno de tales mecanismos ha sido ser miembros activos de procesos participativos institucionales en temas indígenas. Aunque muchas veces estos espacios se convirtieron en campos de batalla simbólica debido a que quienes asistían eran excluidos por representar una comunidad étnica no oficial, con el paso del tiempo también les permitieron adquirir cierto reconocimiento institucional (Gómez Montañez, 2009).

Lo que pasa es que nosotros llevamos hace años un proceso en esto hacia el reconocimiento y venir participando en espacios institucionales: consejos de cultura, consejos de ambiente, donde hay una posibilidad de que el indígena esté. Y pues eso ha generado el ganarse ciertos espacios institucionalmente, como un reconocimiento institucional, digamos. (Rodrigo Niño Rocha, 18 de diciembre del 2011)

A falta de resoluciones, autos u oficios emitidos por la DGAI que certifiquen su existencia como parcialidad indígena, el reconocimiento institucional, según el сммт (Cabildo Mayor Muisca de Tunja) de PNMC, de algún modo ha estado supeditado al grado de convencimiento que ciertos funcionarios tengan respecto a la labor y gestión de la comunidad; de esto dependen los líderes para ser invitados a participar en mesas de consulta y consejos de temas indígenas. Por ejemplo, la ayuda que Rodrigo brindó en el año 2007 a una comunidad embera, en Boyacá, le dio cierta visibilidad y protagonismo que se reflejó en un reconocimiento institucional por parte de la Personería Municipal de Tunja, en 2011.

Pues bien, esta historia, nutrida de numerosos tránsitos y momentos críticos y en la que además es sustancial la discursividad que legitima o brinda esencia y contenido a la agencia de PNMC, está condensada en el siguiente relato de Rodrigo, que cito in extenso:

Hacia el 2007 hubo desplazados de los embera y nosotros los acogimos en la gueta, donde vivíamos en el campo. Primero les sacamos 
una casa en arriendo en un barrio mientras definían la situación con ellos. El Gobierno no hizo nada. Entonces gestionamos eso y los llevamos para allá, y a Fagua [vicegobernadora de CMMT de PNMC] le tocaba ir a la plaza de mercado a conseguir mercados y toda esa cosa regalado. Entonces ahí nos conocieron institucionalmente la labor que estábamos haciendo nosotros los muiscas apoyando a los embera. Pasó así, y a comienzo del año [2011] el personero actual, el personero municipal de Tunja, hubo otro desplazamiento de emberas y el hombre fue brusco con los emberas y un profesor me llamó [...] sin embargo, yo voy a hablar con el personero, y fui y me presenté, y el man cero de los muiscas. Entonces yo le dije que todo lo que pase en el territorio de Boyacá tiene que ver con el territorio muisca, yo soy el responsable porque soy el gobernador, entonces, por lo tanto, yo vengo a mirar qué fue lo que pasó, a tener claridad de las cosas. Le conté la anécdota que tuvimos con los emberas hace tantos años y entonces había una funcionaria y una abogada, y dijo: "Ah, sí, yo recuerdo, ellos hicieron eso". Después de que nos sentamos como casi dos horas a hablar sobre eso, porque el man no sabía ni carajo de eso, entonces dijo: "Pues, hermano, qué pena con ustedes, porque yo no he escuchado de ustedes". [Rodrigo responde:] "No sé, tal vez nos conocíamos, no nos presentamos, pero nosotros estamos posesionados aquí en el cabildo y usted debía saber del tema, debió tener en cuenta eso". Y dijo: “Ustedes no están en la mesa de protección social, de política social del departamento". [Rodrigo responde:] "Yo llevo hace ocho años de ser incluido en la mesa de desarrollo humano y no ha sido posible que se nos tenga en cuenta, porque no somos reconocidos". Y nos dijo: "No, un momento". Y ipum!, el oficio; nos incluyeron en las mesas de política social a los muiscas. Se hizo una reunión, me llegaron los oficios, como gobernador indígena de allá de la gobernación. Ahí tengo los documentos: Xieguazinsa Ingativa, gobernador de Pueblo Nación Muisca Chibcha de Boyacá, está cordialmente invitado como quiera que los muiscas tienen un proceso creciente en este departamento, lo invitamos de ahora en adelante hacer parte de la mesa de política social. Y en esa reunión se sentaron todos los de 
política social, el alcalde de Tunja, acción social, bueno, todas las instituciones representativas de Boyacá. Ahí estaba la Secretaría de Desarrollo Humano de la Gobernación, que es la que maneja grupos poblacionales, entonces allá la charlamos. Y alguien me hizo la pregunta: “¿Por qué hasta ahora sabemos de ustedes?”. [Rodrigo responde:] "Y no, nosotros hemos venido incursionando con la doctora Victoria, la verdad no nos ha tenido en cuenta, porque no estamos reconocidos legalmente, pero eso no quiere decir que no existamos”. Entonces ahí se desató una polémica con el de Acción Social: "Pero aquí en el censo no existen muiscas, ¿cuándo?”. [Rodrigo responde:] “El censo no se hizo bien y nosotros no nos manifestamos frente a este tema, porque ustedes dicen que como no estamos reconocidos, pues no tenemos derechos y preferimos quedarnos quietos; nosotros seguimos en nuestros usos y costumbres y tenemos nuestro cabildo, etc., y sí estamos interesados y estamos haciendo la gestión para llegar al reconocimiento". Entonces ahí empezamos. (Rodrigo Niño Rocha, 18 de diciembre del 2011)

Cada cabildo mayor de PNMC agrupa varias parcialidades correspondientes a localidades y municipios de Bogotá, Cundinamarca y Boyacá. Boyacá es el lugar donde más comunidades muiscas fueron consideradas desaparecidas desde el siglo XIX; allí, grupos de personas y familias se estaban autorreconociendo indígenas y manifestaban su intención de articularse con PNMC para conformar consejos indígenas muiscas o pequeños cabildos en sus municipios. Uno de estos grupos que se fortaleció y dio el paso hacia el autorreconocimiento fue el de Tundama (Duitama). Nuevamente, haciendo evidente la articulación de ciertos primordialismos emotivos activados y la instrumentalización burocrática, quince personas se reconocieron indígenas y formaron el CimT (Consejo Indígena Muisca de Tundama) el 28 de marzo del 2009. El acto fue protocolizado mediante un documento titulado "Declaratoria de autorreconocimiento", con el Acta n. ${ }^{\circ}$ 001-09, que fue notariado y presentado en la Alcaldía Municipal de Duitama. Los cinco puntos mediante los cuales los interesados expusieron lo que adoptaban y promulgaban — como parte del lenguaje oficial— fueron numerados 
en lengua muisca: Ata (1), Bosa (2), Mihca (3), Muhica (4) y Hysca (5). En el primero aclaran que su autorreconocimiento es "formal, libre y voluntario" y que se sujetan tanto a las leyes colombianas como a la "Ley de Origen, Derecho Mayor o Derecho Propio" de los pueblos indígenas. Además afirman que se articulan al proceso de "recomposición étnica y organización" de PNMC en Boyacá. En el segundo aclaran que el CIMT coordinará acciones de vigilancia de los derechos, cultura y territorio indígena en su localidad. En el tercero apelan a los "principios de autonomía y libre determinación de los pueblos indígenas" para declarar su plena autonomía. En el cuarto, con un lenguaje más romántico, se declaran "protectores" del "territorio sagrado ancestral", del patrimonio, de las tradiciones, la lengua y de la "Madre Tierra". En el quinto se comprometen a "empoderar la memoria histórica" de la etnia muisca. En este último punto, además, configuran brevemente una cosmología y narrativa mitológica en la que se definen las "espiritualidades originarias, los "padres creadores" y hasta los llamados "mártires", categoría en la que nombran figuras de la historia de la Conquista que fueron sometidas y asesinadas por los españoles, sobre las cuales declararon "honramos su memoria con nuestra presencia en estos tiempos". En suma, en el documento no solo atravesaron un ritual administrativo y burocrático, sino que puntualizaron las relaciones concretas entre su conciencia étnica, la articulación organizativa y el compromiso moral con la memoria colectiva con la cual se identificaban y anclaban desde el presente.

La Ley 89 de 1890 determinó que las comunidades indígenas deben nombrar un cabildo conforme con sus costumbres, el cual debe posesionarse anualmente y sus autoridades deben ser renovadas. Un acto de posesión de esta naturaleza en cierta manera es una encrucijada para las instituciones, pues al momento de realizar la posesión ante una alcaldía municipal, por ejemplo, esta actúa como testigo del hecho de considerar a las comunidades indígenas organizaciones con autonomía que se rigen bajo lógicas normativas diferentes a la de la población general de la nación. Sin embargo, cuando el Cabildo Mayor Muisca de Chunza quiso posesionarse por primera vez en el 2010, encontró un obstáculo: el secretario de Cultura y Turismo de Tunja, entidad municipal ante la cual el cabildo se posesionaría, creyó que su papel no era 
de testigo, sino de certificador de la existencia étnica de esta organización, por consiguiente, solicitó un concepto a la Secretaría Jurídica. Dicho concepto aclaraba que "de ninguna manera" un alcalde o persona asignada por este puede negarse a posesionar una autoridad indígena, ya que una comunidad étnica tiene derecho al reconocimiento, al trato diferencial y a la autorrepresentación (Oficio CSJ 015, 10 de mayo de 2010 $)^{38}$. El secretario de Cultura y Turismo tuvo que posesionar al Cabildo Mayor Muisca de Chunza, organización no reconocida oficialmente por la DGAI del Ministerio del Interior. Tiempo después, seguramente debido a las sospechas o dudas que le dejó sembradas este hecho, el secretario solicitó que el concepto jurídico emitido aquella vez fuese revisado por la secretaria jurídica de turno, quien concluyó que todo se había ajustado a la ley.

El principio y criterio de la libre determinación, que sustenta el autorreconocimiento, alcanzó niveles inesperados en el marco del reconocimiento étnico. Bajo su aplicación, un grupo de personas se declararon miembros de una comunidad indígena en Duitama. Pero un caso que llevó la legitimidad de PNMC a otro nivel y que desafió el aparataje institucional fue la tutela sentenciada a favor de Víctor Julio Tocarruncho, joven miembro de PNMC en Boyacá. Víctor instauró la tutela al comandante del Distrito Militar 7 de Tunja por "vulnerar su derecho a la vida, al libre desarrollo de la personalidad y a la protección de la diversidad étnica" (Corte Constitucional, Sentencia T-792 de 2012) ${ }^{39}$. Todo obedecía a que el joven deseaba quedar exonerado de prestar el servicio militar obligatorio, apelando, entre otras cosas, a su condición de indígena autorreconocido de PNMC.

A Víctor se le solicitó adjuntar varios documentos que sustentaran su situación personal, entre estos la certificación de PNMC dada por la DGAI. Ante la imposibilidad de presentar tal documento, Víctor argumentó que la legitimidad de PNMC estaba fundamentada en las tres posesiones consecutivas que el Cabildo Mayor Muisca de Tunja había

38 Oficio facilitado por PNMC de Boyacá.

39 Agradezco infinitamente a María Fernanda Palma, colega de Penn University por hacerme saber de esta sentencia y hacérmela llegar. 
realizado en cabeza de su gobernador Rodrigo Niño. Además, alegó que PNMC formaba parte del Consejo de Política Social Departamental de Boyacá desde hacía dos años, lo que le daba legitimidad y reconocimiento institucional. La corte solicitó a la DGAI información sobre PNMC, a lo que respondió que los únicos cabildos muiscas reconocidos eran los de Cota, Chía, Suba, Bosa y Sesquilé. Por su parte, el Icanh (Instituto Colombiano de Antropología e Historia) afirmó que no había estudio etnológico sobre PNMC. Al respecto, Rodrigo Niño, siendo gobernador, argumentó que el hecho de no contar con reconocimiento ante el ministerio público "no puede ser óbice para que se nieguen los derechos que tienen como personas que están en un proceso de 'recomposición étnica', teniendo en cuenta la protección a la diversidad étnica y cultural prevista en la Constitución de 1991" (Corte Constitucional, Sentencia T-792 de 2012). Como pruebas de la existencia de su comunidad étnica presentó un copioso conjunto de cartas y certificados de cabildos indígenas reconocidos y de instituciones públicas que constataban la participación de esta comunidad en algún proyecto, consejo o consulta. También presentó uno de mis libros (Gómez Montañez, 2009), argumentando que en ese estudio yo cuestionaba las fronteras jurídicas, políticas y antropológicas del reconocimiento étnico.

La corte en primera instancia concluyó que "la demostración de la condición indígena de un sujeto debe darse a partir de la identidad cultural real de la persona indígena, esto es, a partir de las consideraciones en torno a la autoidentificación a una determinada comunidad y la aceptación por parte de dicha comunidad" (Corte Constitucional, Sentencia T-792 de 2012). Además, citando la Ley 48 de 1993, determinó que las pruebas presentadas por la misma comunidad para certificar a un miembro tienen "mayor peso" en lo atinente al principio de su libre autonomía. Lo más destacado de la sentencia, sobre el tema que hemos venido desarrollando, es la manera como el juez interpretó la tensión entre los criterios objetivos y subjetivos de identificación étnica:

En este orden de ideas, debe la Corte precisar que el registro ante la Dirección de Etnias del Ministerio del Interior tiene un alto valor probatorio, además de la importancia que tiene a nivel de las gestiones administrativas, pero no es el instrumento definitivo 
para establecer si una comunidad es titular del derecho al reconocimiento y respeto de su diversidad étnica y cultural. Para dirimir este asunto es necesario tener en cuenta la identidad indígena real de la comunidad, tomando en consideración los elementos subjetivos y objetivos que permiten llegar a tal conclusión. Además, es preciso que estos criterios sean interpretados bajo el respeto al principio de buena fe, el derecho a la libre determinación de los pueblos indígenas, el derecho al debido proceso, y la consideración de los pueblos indígenas como sujetos de especial protección. (Corte Constitucional, Sentencia T-792 de 2012. El énfasis es mío)

La tutela falló a favor de Víctor. Fue aceptada su condición étnica a partir de su pleno autorreconocimiento y fue exonerado del servicio militar obligatorio. Pero la única parte beneficiada no fue Víctor; para el Cabildo Mayor Muisca de Chunza el fallo significa un ritual de paso jurídico que legitimó su existencia como etnia, sin importar su certificación de la DGAI. Esta sentencia seguramente formará parte del grueso archivo de Rodrigo, accesible para cuando un nuevo momento crítico se presente y sea necesario demostrarle a otros, incrédulos o no, que los muiscas sí existen en Boyacá.

Brevemente se puede decir entonces que PNMC desafía el campo etnopolítico muisca así. Al igual que los jóvenes de Cota, Víctor fue exonerado de prestar el servicio militar. Aquellos obtuvieron su certificación por parte del cabildo al hacer trabajo social, construyendo la Casa Indígena. Víctor fue certificado por Rodrigo por su plena identificación. Los primeros podrían reclamar una identidad mejor demostrada gracias al reconocimiento oficial que gozan sus comunidades. Víctor puede seguir sustentando la suya si apela a elementos tan distintivos como su apellido, Tocarruncho, o al reconocimiento institucional que PNMC ha logrado tener en Boyacá. Lo cierto es que en ambos casos la identidad indígena otorgó el derecho a la protección de la integridad de las comunidades étnicas. Autorreconocerse indígena sin pertenecer a una comunidad oficialmente certificada implica, como se vio en los casos de Cota, Chía, Sesquilé, Bosa y Suba, tener una conciencia étnica para diferenciarse de otros y a la vez poder operar los instrumentos políticos para garantizar su aplicación. 


\section{Sumario: etnicidades transicionales}

El marco político configurado a partir de la Constitución Política de 1991 estableció dos derechos que fortalecieron los procesos de reconocimiento étnico en Colombia y que, por lo tanto, influyeron notoriamente en la consolidación de un campo etnopolítico muisca. El primero fue el derecho a la autodeterminación o autoidentificación, el cual implicó que la conciencia étnica se activara a nivel tanto individual como colectivo en las diferentes comunidades muiscas, las cuales tuvieron que convencerse a sí mismas de su condición étnica o fortalecerla y hacerla más reflexiva y explícita. El segundo derecho fue el de la autonomía, el cual, gracias al poder que conlleva, significó convencer a las instituciones estatales de la existencia actual del muisca. Los primordialismos más esenciales y los instrumentalismos más racionales. Los primeros fortalecieron orgullos familiares, cohesionaron emotivamente a las comunidades, identificaron la diferencia étnica del campesinado cundiboyacense y le dieron contenido y anclaje histórico al despliegue de dispositivos burocráticos, administrativos y políticos propios de los segundos.

Los primordialismos e instrumentalismos corresponden a instancias temporales del proceso de reconocimiento étnico y no a enfoques determinantes que caracterizan de una u otra forma la etnicidad muisca, por eso mismo se activan en momentos críticos, dándole así a la etnicidad un carácter procesual, transicional, liminal y performativo al atravesar ella misma rituales simbólicos y jurídicos en los planos personales, familiares y comunitarios. Como un modelo replicante, cada vez que algún factor interno o externo amenaza la existencia étnica, el aparataje probatorio se despliega. Además, como performance, asumir la identidad étnica es un ritual de paso que transforma constantemente al sujeto original. Eso también enmarca a los grupos étnicos en la historia y los caracteriza como procesos y entidades complejas y heterogéneas.

Los itinerarios de sentido cursados por las denominaciones indio, nativo, persona de campo, marmato e indígena son los indicadores iniciales de la condición transitoria y transicional de la identidad étnica. Por eso, en los testimonios y relatos de los comuneros, ser muisca 
es algo en lo que ya se lleva un tiempo, algo que se incorpora, algo que no se sabía pero que se aprende, algo que se niega y que luego se acepta. Pero también es algo que se otorga o niega de acuerdo a criterios particulares de las instituciones o de sus funcionarios, así como una categoría que a veces agrupa la totalidad de elementos que identifican a alguien y otras veces permanece al lado de complementarias y contradictorias categorías civiles y políticas. A lo largo de este capítulo mostré entonces que la complejidad transicional y probatoria es tal, que los testimonios personales se complementaron con fuentes jurídicas y administrativas, lo que también demuestra que, tal cual como lo afirmaron Chirot y Seligman (2002), el Estado es el foco de la identidad etnopolítica. 